\title{
The SMOS Mission: New Tool for Monitoring Key Elements of the Global Water Cycle
}

\author{
This satellite mission will use new algorithms to try to forecast \\ weather and estimate climate change from satellite \\ measurements of the Earth's surface.
}

\author{
By Yann H. Kerr, Senior Member IEeE, Philippe Waldteufel, \\ Jean-Pierre Wigneron, Senior Member Ieee, Steven Delwart, François Cabot, \\ Jacqueline Boutin, Maria-José Escorihuela, Jordi Font, Nicolas Reul, \\ Claire Gruhier, Silvia Enache Juglea, Mark R. Drinkwater, Member IEeE, \\ Achim Hahne, Manuel Martín-Neira, and Susanne Mecklenburg
}

ABSTRACT | It is now well understood that data on soil moisture and sea surface salinity (SSS) are required to improve meteorological and climate predictions. These two quantities are not yet available globally or with adequate temporal or spatial sampling. It is recognized that a spaceborne L-band radiometer with a suitable antenna is the most promising way

Manuscript received September 9, 2009; revised December 21, 2009 and January 25, 2010. First published April 12, 2010; current version published May 5, 2010. Y. H. Kerr, F. Cabot, C. Gruhier, and S. E. Juglea are with CESBIO-CNES, Université Toulouse, 31401 Toulouse CEDEX 09, France (e-mail.

yann.kerr@cesbio.cnes.fr; cabot@cesbio.cnes.fr; gruhier@cesbio.cnes.fr; juglea@cesbio.cnes.fr).

P. Waldteufel is with IPSL-LATMOS, 91371 Verrières le Buisson, France (e-mail: Philippe.Waldteufel@aerov.jussieu.fr).

J.-P. Wigneron is with INRA EPHYSE, 33883 Bordeaux, France (e-mail: jpwigner@bordeaux.inra.fr).

S. Delwart, M. R. Drinkwater, A. Hahne, and M. Martin-Neira are with ESA ESTEC, Noordwijk, PostBus 299, 2200 AG, The Netherlands (e-mail: Steven.Delwart@esa.int; Mark.Drinkwater@esa.int; achim.hahne@esa.int; manuel.martin-neira@esa.int).

J. Boutin is with IPSL-LOCEAN, 75252 Paris, France

(e-mail: Jacqueline.Boutin@locean-ipsl.upmc.fr).

M.-J. Escorihuela is with IsardSAT, 08031 Barcelona, Spain (e-mail: mj.escorihuela@isardsat.cat).

J. Font is with ICM-CSIC, 08003 Barcelona, Spain (e-mail: jfont@icm.csic.es).

N. Reul is with Ifremer, Brest, 29280 Plouzané, France (e-mail:

Nicolas.Reul@ifremer.fr).

S. Mecklenburg is with ESA ESRIN, Frascati, 0044 Roma, Italy

(e-mail: Susanne.Mecklenburg@esa.int).

Digital Object Identifier: 10.1109/JPROC.2010.2043032 of fulfilling this gap. With these scientific objectives and technical solution at the heart of a proposed mission concept the European Space Agency (ESA) selected the Soil Moisture and Ocean Salinity (SMOS) mission as its second Earth Explorer Opportunity Mission. The development of the SMOS mission was led by ESA in collaboration with the Centre National d'Etudes Spatiales (CNES) in France and the Centro para el Desarrollo Tecnologico Industrial (CDTI) in Spain. SMOS carries a single payload, an L-Band 2-D interferometric radiometer operating in the $1400-1427-\mathrm{MHz}$ protected band [1]. The instrument receives the radiation emitted from Earth's surface, which can then be related to the moisture content in the first few centimeters of soil over land, and to salinity in the surface waters of the oceans. SMOS will achieve an unprecedented maximum spatial resolution of $50 \mathrm{~km}$ at L-band over land (43 km on average over the field of view), providing multiangular dual polarized (or fully polarized) brightness temperatures over the globe. SMOS has a revisit time of less than 3 days so as to retrieve soil moisture and ocean salinity data, meeting the mission's science objectives. The caveat in relation to its sampling requirements is that SMOS will have a somewhat reduced sensitivity when compared to conventional radiometers. The SMOS satellite was launched successfully on November 2, 2009.

KEYWORDS | Interferometry; L-band; sea surface salinity (SSS); soil moisture; Soil Moisture and Ocean Salinity (SMOS); vegetation water content 


\section{INTRODUCTION AND CONTEXT}

For the last three decades at least, various attempts have been made to make global, frequent estimates of soil moisture and, to a lesser extent, sea surface salinity (SSS) [1]. These attempts were always unsatisfactory for a number of reasons but mainly owing to the lack of appropriate means to measure these two variables directly from space [2]-[5]. In parallel, the need for data on these key variables grew [6]-[12]. Although a low-frequency passive microwave remote sensing approach had been identified as the most promising tool back in the 1970s and 1980s [4], [13], the implementation of a suitable instrument for space application nonetheless remained a significant challenge. At low microwave frequencies the emissivities of land and oceans are strong functions of soil moisture and salinity, respectively. As a result, satellite observations of brightness temperature of Earth's surface, which is equal to the effective emitting temperature of the surface modified by the emissivity, could be used to produce global maps of soil moisture and SSS. In the late 1980s, several solutions became apparent [14]-[16]. However, before the Soil Moisture and Ocean Salinity (SMOS) mission became a reality, the scientific objectives were thoroughly assessed in order to develop and achieve a suitable optimal though entirely new concept [17], [18].

\section{RATIONALE}

\section{A. Rationale for Measuring Soil Moisture}

Soil moisture usually refers to the amount of water stored near the soil's surface. Any soil absorbs a given amount of water before being saturated. It is common knowledge that different types of soils behave in different ways. Generally speaking, soil moisture refers implicitly to near-surface soil moisture. Actually, depending on the use of such information, soil moisture may refer to different quantities. The most usual distinction is made between surface soil moisture and root zone soil moisture. Surface moisture corresponds to the water content in the first centimeters of the soil. Soil moisture interacts directly with the atmosphere through evaporation and also drives infiltration, hence run off during heavy rain events. Most plants have their root system near the surface, but also in the deeper layers of the soil, depending on soil depth and vegetation type. Vegetation growth and health is therefore linked directly to the amount of water available in the root zone. The root zone is very close to what is referred to in hydrology as the "vadose" or "unsaturated zone." Finally, there may be another layer of stored water, deeper in the "saturated zone" or water table. This layer is used by the deepest roots of trees and for man-made wells.

Just to be exhaustive, one must remember that when dealing with mass water transfer between the atmosphere and the soil, there are other areas where water is stored and that have an influence.

- Water stored in vegetation, which had come from the soil can be evaporated into the atmosphere through respiration/transpiration. One may note that for a grass fallow in southwest France, the diurnal variations of vegetative water content are equivalent to a third of the seasonal (i.e., one year) variations [19].

- Water stored above the surface, for example, in lakes, rivers, ponds, snow, and ice, can evaporate or "sublimate," and can percolate or even run off.

- Water intercepted by vegetation during rain events or as dew may also evaporate, be absorbed by the leaves, or eventually fall to the ground.

Consequently, water available in the first centimeters of the soil layer is both a storage and a key to the exchanges between the surface and the atmosphere. Soil Vegetation Atmosphere Transfer (SVAT) models have been developed to represent these heat and mass transfers and simulate these exchanges, taking into account the forcings from wind, solar radiation, rain, etc. SVAT models also take into account the physical state of the surface, such as soil moisture, vegetation type and state, local slope, and roughness. Thanks to these models and observations, we have now some insight into the various factors that are crucial to improving weather forecasts and extreme events. Among them, soil moisture plays an important role as:

- a reservoir of water;

- a source of water that can be evaporated into the atmosphere through mass transfer;

- a tracer of water that fell as rain;

- a factor influencing the nenergy budget at the surface/atmosphere interface since evaporation requires energy and therefore induces a decrease in temperature.

Consequently, a good knowledge of soil moisture should significantly improve our ability to forecast the weather, as well as better predict extreme events [6]-[8], [20]-[23]. Depending on the soil characteristics and surface water content, events such as rainstorms can lead to flooding and even landslides, so having accurate and timely soil moisture data would lead to a better prediction of such hazardous events. Another valuable use of soil moisture data will lead to important information on water availability. One obvious example would be to know whether to irrigate an agricultural field or not depending on its state, the stage of crop growth, its water requirements, and the forecasted weather. This is crucial in arid or semiarid areas where irrigation is very often required but water is scarce.

The SMOS objectives are particularly relevant to the international programs such as Global Energy and Water EXperiment (GEWEX) and in particular to the Global Soil Moisture Network initiative. It is also obviously a significant requirement for International Panel on Climate 
Change (IPCC) related work. However, the most important driver is currently through the national and international weather centers such as the European Centre for Medium range for Weather Forecast (ECMWF).

\section{B. Rationale for Measuring SSS}

Salinity describes the concentration of dissolved salt in water. It is measured in practical salinity units according to the Practical Salinity Scale of 1978 (known as pss-78), which expresses a conductivity ratio and thus dimensionless units but corresponds to grams of salt per liter of water. In the following text, the salinity values imply use of the pss-78 scale.

The average salinity of the oceans is 35 , which is equivalent to approximately $35 \mathrm{~g}$ of salt in $1 \mathrm{~L}$ of water. The distribution of salt in the global ocean and its annual and interannual variability is crucial for understanding the role of the ocean in the climate system. In situ salinity measurements have only been sampled relatively scarcely over the oceans [24]. The distribution of salinity measurements has greatly improved over the last years owing to the increasing density of deployment of Array for Real-time Geostrophic Oceanography (ARGO) floats [25], and the multiplication of measurements on voluntary observing ships and from moored platforms. However, sampling remains irregular and inhomogeneous, partly because ARGO floats very rarely sample divergence zones. With respect to these in situ measurements, remote sensing systems will provide an increased temporal coverage albeit with lesser accuracy [3], [24], [26]. In addition, in situ measurements are usually limited to several meters below sea level, but remote sensing systems have the advantage of monitoring the first centimeter of the sea surface, where in the presence of rain there may be a significant difference in surface salinity values [27]. To date, a significant fraction of tropical ocean areas experiencing convective rainfall remains unsampled. This means that average values of SSS field are known to some extent, but details about variability on seasonal to interannual scales remain hidden. Recently, evidence of multidecadal variability was demonstrated [28]. Knowledge of salinity distribution is also necessary to determine the equation of state. For the calculation of dynamic height anomalies the salinity distribution must be known. For instance, when calculating geostrophic currents using satellite altimetry measurements, better knowledge of the SSS would improve the accuracy of the estimates, for example, a 0.5 pss-78 error in salinity accounts for $3.8-\mathrm{cm} / \mathrm{s}$ error in geostrophic velocity at $1-\mathrm{km}$ depth, calculated from the corresponding surface value.

SSS varies as a result of the exchange of water between the ocean and the atmosphere, via sea-ice freezing and melting and from continental runoff. Salt affects the thermohaline circulation, and therefore the distribution of mass and heat. Salinity may control the formation of water masses, which allows its use for tracer studies. Salinity is also thermodynamically important as salinity stratification can influence the penetration depth of convection at high latitudes and may determine the mixed layer depth in equatorial regions. Positive surface temperature anomalies are suggested to be associated with anomalously strong thermohaline circulation in the North Atlantic.

In tropical areas the salinity is useful as indicator of precipitation and evaporation, thus it play an important role in studies of surface water fluxes. For example, during heavy rainfall freshwater lenses are produced on the ocean surface, which are stable features. They mix slowly with the bulk sea water and can persist from hours to weeks depending on the wind speed conditions [29]. The spatial and temporal scale of precipitation events may also play a role in freshwater lens formation, typical scales, and lifetime. It may also be noted that Henocq et al. [27] recently identified a signal of freshening in upper salinity measurements in the presence of rain. The role of salinity and its change by freshwater fluxes at the atmosphere-ocean interface has to be included also for a full understanding of the entire El Nino Southern Oscillation (ENSO) process [30]. Freshwater input by river and the subsequent spreading of freshwater by the surface oceanic circulation decreases surface salinity and, in addition, it reduces concentration of total inorganic $\mathrm{CO}_{2}$ and, to a lesser extent, alkalinity, leading to a lowering of $\mathrm{CO}_{2}$ fugacity [31]. In addition, the combination of riverine nutrient input and solar radiation creates a highly productive transition zone, the location of which varies with the discharge from the river. Therefore, monitoring the patterns of dispersal of the world's largest river water in the ocean would greatly improve estimation of the fresh water budget, the variability of the air-sea $\mathrm{CO}_{2}$ flux and of the biological productivity.

SSS has been observed only from space with microwave radiometry at sub-basin scale, for example, in the strong horizontal gradient area of the Amazon plume [32]. Space observation on a global scale will be very welcomed as the current knowledge of SSS is rather poor and insufficient to account for the role of salinity in the ocean component of the climate system. The primary scientific objectives of ocean salinity observations provided by the SMOS mission are to:

- improve seasonal to interannual climate predictions by effective use of SSS data to initialize and improve the coupled climate forecast models;

- improve oceanic rainfall estimates and global hydrologic budgets via the new and improved knowledge of the SSS variability;

- monitor large scale salinity events.

These objectives are particularly relevant for the major international ocean programs and their observing system and experiments planned for the next five to seven years including the Global Ocean Observing System (GOOS), Climate Variability and Predictability (CLIVAR), Global Ocean Data Assimilation Experiment (GODAE), and the Global Climate Observing System (GCOS), which are established to coordinate the provision of data for climate monitoring, climate change detection, and response monitoring. 


\section{MEASURING SOIL MOISTURE AND OCEAN SALINITY}

\section{A. How to Measure Soil Moisture}

In all that follows, the term soil moisture, unless specified, will refer to the moisture in the top $5 \mathrm{~cm}$ of soil. Soil moisture is traditionally expressed as either gravimetric (by weight) or volumetric (by volume). The most commonly used unit in remote sensing is the volumetric soil moisture which corresponds to the ratio between volume of water and volume of soil holding the water.

1) At Ground Level: The volumetric soil moisture can be inferred from the gravimetric soil moisture by simply multiplying this value by the bulk density of the soil. Volumetric soil moisture will be the unit used from now on unless otherwise specified and is expressed in terms of $\mathrm{m}^{3} / \mathrm{m}^{3}$.

To achieve the goals mentioned above, it is necessary to have access to soil moisture estimates. At a given point in space and time, this is relatively easy with gravimetric sampling. However, to have measurements representative of a large area, such as a field, the procedure is already somewhat complex as it involves a dedicated sampling strategy. Moreover, as these measurements are time consuming, regional and global coverage is out of question. Provided one uses automatic probes, such as impedance, capacitive, time domain, or reflectometry, it is possible to achieve larger coverage and continuous measurements, but as they require care and maintenance, these approaches can only be confined to well-equipped manned sites. Last, these systems carry their own problems and inaccuracies. From space we have access to a global approach; the measurements are by nature integrated and thus more representative, while ground measurements are by essence very local and gravimetric samples taken a few meters apart may lead to different measurements. Conversely, if ground measurements can be very direct and accurate, measurements from space are bound to be indirect and therefore imply caveats. This raises the general issue of validation of remotely sensed estimates with ground measurements.

2) Remotely Sensed Soil Moisture-The Main Approaches: A large number of remote sensing approaches have been tested. For surface soil moisture, the first ones were based on shortwave measurements and on the basic fact that soils become darker in color when wet. Obviously, due to atmospheric effects and potential cloud cover, as well as vegetation cover masking effects, and very weak sensitivity, this approach is bound to fail in most cases. A more promising feature is linked to latent heat effects. Wet soils have a higher thermal inertia and are "cooler" than dry soils. These properties led to various trials, including thermal inertia monitoring, rate of heating in the morning, and surface temperature amplitude to assess soil moisture indirectly. All these approaches proved to be somewhat disappointing due to factors inherent to optical remote sensing (atmospheric effects, cloud masking, vegetation cover opacity) as well as the fact that i) thermal infrared probes the very skin of soil and ii) the layer probed in thermal infrared is dominated by exchanges with the atmosphere. Consequently, to infer soil moisture from such measurements, one needs to know the exact forcings. Wind, for instance, will drastically change the apparent temperature of wet soil due to turbulent and latent heat, and convective heat losses. As microwave systems measure the dielectric constant of soils, which is directly related to water content, research quickly focused on assessing soil moisture with radar, scatterometers, and radiometers. When operated at low frequency, these systems offer the added advantage of being all weather. Their measurements are not affected much by the atmosphere and clouds; they are able to penetrate vegetation, and in addition can operate in darkness. Moreover, at low frequencies, the penetration depth is significant, typically $5 \mathrm{~cm}$ at L-band, making the estimates both less sensitive to forcings and therefore more representative.

Finally, in an attempt to be exhaustive, a new approach relies on measurements of the gravity field from space. As gravity is linked to mass, one may consider that changes in mass on short time scales are mainly linked to changes in the total amount of water. However, water in this case could include the water table, water in soil layers, possibly lakes, rivers, snow, and ice, in vegetation and in the atmosphere. Time-variable gravimetry thus indicates changes in the total column of water at river basin/ catchment scales of $500 \mathrm{~km}$ or greater. The results from Gravity Recovery And Climate Experiment (GRACE) mission certainly show strong seasonally varying signals, but the relationship with water storage has yet to be validated and explained. The main problem with such measurements is that they require a very large number of corrections, which can be very sophisticated, for instance, orbital corrections or taking into account the influence of tides and post glacial rebound. These corrections are prone to degrade the error budget in a case where the errors and corrections are of equivalent magnitude to the signal to be measured.

3) Microwaves as a Tool for Soil Moisture Monitoring: The most popular approach relies on the use of synthetic aperture radars (SARs). These systems, in use since 1978 with SEASAT, offer all weather measurements with a fine spatial resolution in the order of tens of meters. However, for operational use, their measurements suffer-as with most high-resolution systems - from a rather low temporal sampling; 35 days revisit for the European Remote Sensing (ERS) satellite, for instance. This is not really compatible with hydrologic requirements or weather forecast models. However, the most adverse characteristic of SAR is the coherent nature of the signal itself and the interactions 
with the scattering medium. SAR images are affected by speckle and by the scattering at the surface. The scattering can be due to the vegetation cover, such as distribution of water in the canopy, or the soil's surface-surface scattering when wet, and volume scattering when dry. The direct consequence of these perturbations is a signal at least as sensitive to surface roughness as to moisture itself (see also [33]) not to mention vegetation. Obviously these effects are frequency dependent. All these inherent difficulties might explain why no absolute soil moisture mapping has been done by the several SAR systems that have flown since 1978. To avoid the roughness and vegetation perturbations, an approach relying on change detection, hence relative, has been used with some success [34]. However, temporal coverage is still often an issue.

The use of scatterometers offers an interesting tradeoff. The spatial resolution is much coarser, on the order of tens of kilometers, but with a much wider swath allowing reasonably frequent coverage, around 4-6 days on average. It also offers the added advantage of being less subjected to speckle (averaging). Consequently, several authors routinely produce soil wetness index maps from scatterometer data of many areas of the world [2], [35], [36]. The effect of vegetation is, however, still significant and actually corresponds to most of the signal at the currently available frequencies of C-band (on ERS-1) and higher. Consequently, the most interesting results have been obtained over arid and semiarid regions, for which variations in vegetation and soil moisture are very highly correlated [37]. The influence of surface roughness is also significant and is best dealt with by using change detection methods.

The last possibility in the microwave domain is to use radiometers. The technique is old and well mastered as many sensors, notably sounders, rely on passive microwaves. Measurements of soil moisture with low-frequency radiometers are based on the fact that emissions from the Earth show a large contrast between water and land due to the large difference between the relative permittivities or dielectric constants of water and dry soil. The attenuation of the emitted radiation due to vegetation is moderate at low frequency. At L-band, for instance, the influence of vegetation on the signal can be accounted for in vegetated areas with a biomass corresponding to an integrated water content of less than $5 \mathrm{~kg} / \mathrm{m}$ (corresponding to $65 \%$ of Earth's land surface [1], [2]). To infer soil moisture, these systems are bound to offer the best compromise if used at low frequency, as demonstrated in the early 1970s with the very short Skylab mission. However, to be efficient, one needs to work in a protected frequency band to avoid unwanted man-made emissions and radio frequency interferences (RFI) and to be sensitive to soil moisture while minimizing the effects of propagation through the atmosphere and vegetation.

At L-Band, the emissivity may vary from almost 0.5 for a very wet soil to almost 1 for a very dry soil, giving a range of $80-100 \mathrm{~K}$ for an instrument sensitivity usually of the order of $1 \mathrm{~K}$ [5]. As the signal is not coherent, surface roughness and vegetation structure play a reduced role by comparison to active systems. So, one may wonder why L-band radiometry was not used extensively before when it was proved to be most efficient during ground and airborne measurements [38]. This is due to an inherent limitation: the spatial resolution is proportional to the antenna diameter and inversely proportional to the wavelength. At $21 \mathrm{~cm}$, to achieve a $40-\mathrm{km}$ resolution from an altitude of $750 \mathrm{~km}$ requires an antenna of about $8 \mathrm{~m}$ in diameter, which is a very significant technical challenge. So in recent years research has been performed using data from available higher frequency systems such as the scanning multichannel microwave radiometer (SMMR; 6.6 GHz) [39], the special sensor microwave imager (SSM/I; $19 \mathrm{GHz})$, and now the advanced microwave scanning radiometer (AMSR-E; $6.8 \mathrm{GHz}$ ) [40]. Despite the nonoptimal frequency and very poor resolution due to antenna side lobes, good results have been obtained with SMMR and AMSR-E. The primary limitations are mainly linked to the fact that the vegetation becomes rapidly opaque, and the frequency is not protected and thus bound to be polluted by RFI. The single angular measurement also makes it difficult-in several cases - to separate vegetation and soil contributions from the signal.

Moisture and salinity influence the respective emission characteristics of soil and seawater and thus the emitted microwave radiation from Earth's surface. The retrieval of soil moisture from emitted radiation, expressed in brightness temperatures $(\mathrm{Tb})$ has to consider a variety of instrument parameters, such as radiometric sensitivity and accuracy, calibration stability, and interferometric image reconstruction. Surface characteristics also have to be accounted for, such as soil surface roughness and texture, land cover, surface heterogeneity, dew, rain interception, snow, topography, litter effect, and surface water, as does radio-frequency interference [41].

a) Vegetation: In order to retrieve soil moisture it is necessary to account for the vegetation layer above the surface [42], [43]. As the accounting has to be as accurate as possible it may be useful to infer the actual vegetation water content (since this information is used in flux assessment, vegetation state, stress, etc.). Of course the retrieval will be the total integrated water contentvegetation water content at the time of overpass plus possibly water interception, for instance. It may be noted that this quantity is not necessarily directly related to the vegetation cover as derived from an optical sensor [44]. Assuming that vegetation varies less rapidly than soil conditions in time, a retrieval once a week should be sufficient to monitor vegetation integrated water content, provided the measurements are made at the same time of day to reduce the impact of diurnal changes in vegetation integrated water content, and accepting the idea that at large resolutions of $40 \mathrm{~km}$, rain interception spatial 
Table 1 Overview of SSS Variability for Given Areas and Processes Together With the Characteristic Temporal and Spatial Scales as Well as Retrieval Accuracy [24]

\begin{tabular}{|c|c|c|c|}
\hline Area and process & Accuracy & $\begin{array}{c}\text { Horizontal } \\
\text { Resolution }\end{array}$ & $\begin{array}{c}\text { Temporal } \\
\text { sampling }\end{array}$ \\
\hline Unit & $(\mathrm{pss}-78)$ & $(\mathrm{km})$ & \\
\hline \hline Coastal processes & 1 & 20 & $1-10$ days \\
\hline ENSO & 0.1 & 100 & 1 month \\
\hline $\begin{array}{c}\text { Tropical Circulation } \\
\text { (buoyancy driven) }\end{array}$ & 0.3 & 50 & $1-3$ days \\
\hline $\begin{array}{c}\text { High latitude } \\
\text { fronts/eddies }\end{array}$ & 0.2 & $50-100$ & 10 days \\
\hline Freshwater lenses & $0.1-1.0$ & 50 & $1-10$ days \\
\hline Great salinity anomalies & 0.1 & 100 & $1-6$ months \\
\hline Largest river plumes & $0.5-1$ & $20-50$ & $\begin{array}{c}10 \\
\text { days-1month }\end{array}$ \\
\hline
\end{tabular}

distribution will be somewhat smoothed out. Finally, it must be also acknowledged that freezing will considerably affect the signal over land. When it freezes, short vegetation becomes transparent and soils appear dry [45].

\section{B. How to Measure SSS}

1) At Sea Level: As for soil moisture, measurement of SSS has presented a significant challenge for a long time. The only direct means of measuring this variable has been through sampling which, over the oceans, is even more daunting than over land. Consequently, for a long time the only means was to take samples along the coast and from ships and the resulting measurements were thus sparse. In spite of these limitations, maps were produced [46], [47] and climatology derived, though with very few data in large areas. This situation changed drastically with the implementation of conductivity measurements on tropical moorings; Tropical Atmosphere Ocean Project (TAO) in the Pacific Ocean, the Prediction and Research Moored Array in the Atlantic (PIRATA), and the Research Moored Array for African-Asian-Australian Monsoon Analysis and Prediction (RAMA) in the Indian Ocean. A further advance has been achieved with the deployment of ARGO profiling floats that provide a measurement every 10 days in each $2^{\circ} \times 2^{\circ}$ grid boxes over all the oceans of the globe, up to 5-m depth [48]. In addition, drifting buoys measuring at $10-50-\mathrm{cm}$ depth provide a new means of monitoring salinity variability within the top meter of the ocean [49].

2) Remotely Sensed SSS: From space, the only direct mean to remotely assess SSS is through the use of passive microwaves. The dielectric constant of seawater is a function of its salinity and temperature [50] and directly impacts sea surface emissivity. The sensitivity of the $\mathrm{Tb}$ to SSS at L-band (1.4 GHz) is well established [3], [4]. It is at a maximum at low microwave frequencies, depending on ocean temperature, incidence angle, and polarization [51], [52]. However, the absolute sensitivity of Tb to SSS changes is low, also depending on temperature: sensitivity decreases from $0.5 \mathrm{~K} / \mathrm{pss}-78$ in $20{ }^{\circ} \mathrm{C}$ water to $0.25 \mathrm{~K} / \mathrm{pss}-78$ for an SST of $0{ }^{\circ} \mathrm{C}$ [3], [4]. Hence, strong demands are put on the SSS retrievals from space in polar and subpolar regions where the water masses are very sensitive to small changes in SSS (below 0.1 pss-78). Other oceanic factors that will influence the brightness temperature retrievals at L-band are surface roughness (wind speed and direction) [52] and foam. Precise estimates for the uncertainties associated with these features are required in order to obtain sufficiently accurate SSS retrievals from space. The characteristics of the surface salinity variability and its effects on the ocean show large regional differences from the equatorial and tropical region via the midlatitudes to the high latitudes. An overview of these characteristics in terms of required retrieval accuracy and corresponding resolution for the SSS measurements are given in Table 1. Furthermore, the low radiometric sensitivity limits the accuracy for salinity estimates from a single pass, which makes temporal and spatial averaging necessary. Consequently, SSS retrieval is a much more significant challenge and all the perturbing factors must be accurately taken into account. Atmosphere is nonnegligible in locations where persistent atmospheric signatures (e.g., the intertropical convergence zone) may impact up to monthly averaged SSS products [53]. Additionally, Faraday rotation in the ionosphere must be accounted for [54], [55], as well as the galactic contribution [56], Sun reflection, etc. [51], [57]-[59]. Even with all these precautions the radiometric sensitivity required to infer SSS within $0.1 \%$ is not possible with a standard radiometer as it would require a sensitivity of around 0.01 K [4], [9], [51], [60].

In general, temporal and spatial averaging improves the retrieval accuracy as long as both i) excellent stability and calibration of the radiometer is ensured [1], [18], [61] and ii) potential biases in the retrieved SSS from single pass measurements are not persistent within the averaging space-time window. From Table 1, it follows that an accuracy of 0.1 pss-78 over a distance of $100-200 \mathrm{~km}$ for a time period of about one week is an optimized requirement 
Table 2 SMOS Mission Requirements for Soil Moisture and Ocean Salinity

\begin{tabular}{|c|c|c|c|}
\hline Variable & Accuracy & $\begin{array}{c}\text { Spatial } \\
\text { resolution }\end{array}$ & $\begin{array}{c}\text { Temporal } \\
\text { sampling }\end{array}$ \\
\hline \hline Soil moisture & $0.04 \mathrm{~m}^{3} / \mathrm{m}^{3}$ & $<50 \mathrm{~km}$ & $<3$ days \\
\hline Vegetation water content & $0.1 \mathrm{~kg} / \mathrm{m}^{2}$ & $<50 \mathrm{~km}$ & $<5$ days \\
\hline Sea Surface salinity & $\begin{array}{c}0.1-0.2 \\
\mathrm{pss}-78\end{array}$ & $100-200 \mathrm{~km}$ & $10-30$ days \\
\hline
\end{tabular}

for description and quantification of many central ocean processes. As such, it will satisfy the requirement given for SSS measurements in the context of the Global Ocean Data Assimilation Experiment (GODAE). ${ }^{1}$

\section{Summary of Requirements}

The following mission requirements for soil moisture observations were derived from the scientific objectives [18].

- Soil moisture accuracy $\left(0.04 \mathrm{~m}^{3} / \mathrm{m}^{3}\right.$ or better). For bare soils, for which the influence of soil moisture on surface water fluxes is strong, it was shown that a random error of $0.04 \mathrm{~m}^{3} / \mathrm{m}^{3}$ allows an acceptable estimation of the evaporation and soil transfer parameters. Moreover, this value corresponds to the typical root mean square (rms) dispersion of in situ soil moisture observations.

- Spatial resolution $(<50 \mathrm{~km})$ : A $20-\mathrm{km}$ pixel size (smaller whenever possible) would be adequate. Larger than $50 \mathrm{~km}$ is too large for mesoscale models. Moreover, the number of watersheds covered by a sufficient number of pixels (40 or more) would be small.

- Revisit time (3-5 days): To track the quick drying period after rainfall, which is very informative to determine soil hydraulic properties, a 1- or 2-day revisit time is optimal. A 3-5-day revisit time is found to be acceptable to define root zone soil moisture and evapotranspiration but ancillary information on rainfall are then required.

- Time acquisition: The precise time of the day for data acquisition is not critical for ocean applications. However, as Faraday rotation is minimal around 6 A.M., it is a preferred choice. Over land at 6 A.M., it may be expected that the conditions will generally be as close as possible to thermal equilibrium with a minimal water profile gradient, optimizing the retrieval efficiency.

Requirements for SSS observations are given in Table 1. At high latitudes (North Atlantic, subpolar seas) the requirements are most demanding as the brightness/SSS ratio at low water temperatures is lower.

${ }^{1}$ http://www.bom.gov.

\section{EMERGING SPACE CONCEPTS}

From all the above it is clear there is a dire need of both soil moisture measurements and SSS retrievals as they are key parameters of the Earth system. To access them in a global and reliable fashion it seems that, even if complemented by other measurements, L-band radiometry is currently the best choice. The advantages are linked to an optimal tradeoff between high sensitivity to soil moisture and SSS versus antenna size and Faraday rotation effect, minimal impact of atmospheric effects, and the fact that the L-band has a protected bandwidth (1400-1427 MHz), reducing the RFI risk. So, up to the late 1980s, the main limiting factor for an L-band radiometer was antenna size.

Two options could be envisaged in terms of antenna: either use of a real aperture antenna or a synthetic one. If a real antenna option had been selected, again two options were possible: either relax the antenna size constraint or devise a means to deploy a large antenna in space. Using a smaller antenna meant degrading the spatial resolution and was quite acceptable when the priority was signal purity rather than spatial resolution as encountered over ocean surfaces. National Aeronautics and Space Administration's (NASA) Aquarius satellite mission is an example of this option with a moderately large antenna used in a push broom mode with three contiguous beams of around 100-km spatial resolution to achieve a 300-km swath [62]. The other option was to devise a way to embark a large but deployable antenna. This venue was explored with many different approaches including HydroSTARS (1-D interferometry), IRIS, and OSIRIS in the 1990s. The latter were based on inflatable antennas that would be eventually discarded for the deployable light wire mesh antenna-a robust concept already used in several satellites with antennas of $>10 \mathrm{~m}$. This concept was proposed for HYDROS [63] and is currently being investigated under the name of soil moisture active and passive (SMAP). It is a 6-m rotating antenna. It is worth also noting that both Aquarius and SMAP will carry an active L-band system along with the radiometer. The second option consists in using a synthetic aperture as chosen for SMOS and as described below. Obviously SMOS was designed to fulfil the requirements detailed in Table 2 and logically these requirements are similar to those of Aquarius and SMAP. The main difference is that SMOS relies on a new instrument and antenna concept. 


\section{THE SMOS CONCEPT}

\section{A. SMOS Inception}

So, considering the necessity to make L-band measurements, other approaches have been tested to overcome the antenna size issue. The first was initiated in the early 1990s with the idea of applying radio astronomy techniques (very large arrays and very large baseline interferometers) to remote sensing [15]. The 1-D concept, electronically scanned thinned array radiometer (ESTAR), was implemented as an aircraft version and proved to fulfil the requirements [14]. It is a system, deployable in space as a sort of large rake that offers-at the cost of a reduced sensitivity - an acceptable spatial resolution. Such concepts were proposed without success to space agencies on several occasions, the best example being HydroSTAR. The concepts appeared to be complex to deploy and to run, or offer limited measurements (single angle and frequency) as well. By 1990, a small group had started work on the development of a similar instrument [64] quickly evolving into a 2-D concept [65]. The concept was named microwave imaging radiometer with aperture synthesis (MIRAS) and an airborne prototype was made and operated [66]. From then on, the concept evolved into a more tailored instrument under the name of the SMOS mission. Fig. 1 shows an artist's view of the satellite.

a) Mission: The SMOS concept was fine tuned by using all the degrees of freedom of the mission (altitude, time of equator ascending crossing, inclination, tilt $\mathrm{T}$ and steer angle $\mathrm{S}$, antenna spacing, number of elements per arm, etc.) to optimize the satellite mass and power budget, while satisfying the mission objectives. Starting with the basic design of a Y-shaped instrument and the overall constraints, an optimization study was performed [67]. The aim was to work on the retrieval outputs and see which configurations would give the best results and satisfy the specifications, rather than working on brightness temperatures only. For instance, over land, the swath (hence the revisit) is defined by the across-track distance up to which successful soil moisture retrievals can be done for nominal targets (nonforested areas) with an accuracy better than $0.04 \mathrm{~m}^{3} / \mathrm{m}^{3}$. All other noises and perturbations were included and for a pixel whose 3-dB limits have a large and small axis average less than $50 \mathrm{~km}$ and a ratio less than 1.5 (see Fig. 2). To achieve such characteristics, the altitude and steer angle [angle of the arms with respect to the velocity vector; see Fig. 2(a)] are adjusted as a function of the antenna spacing (for more details, see [67]. Over the ocean the constraints are less on the spatio-temporal revisit and more on the sensitivity and stability, together with reduction of perturbing factors. Fig. 2(a) shows the geometry while Fig. 2(b) depicts the plot of the idealized field of view. The grid is in kilometers and the main limits are indicated for the whole field of view over land, as explained above.

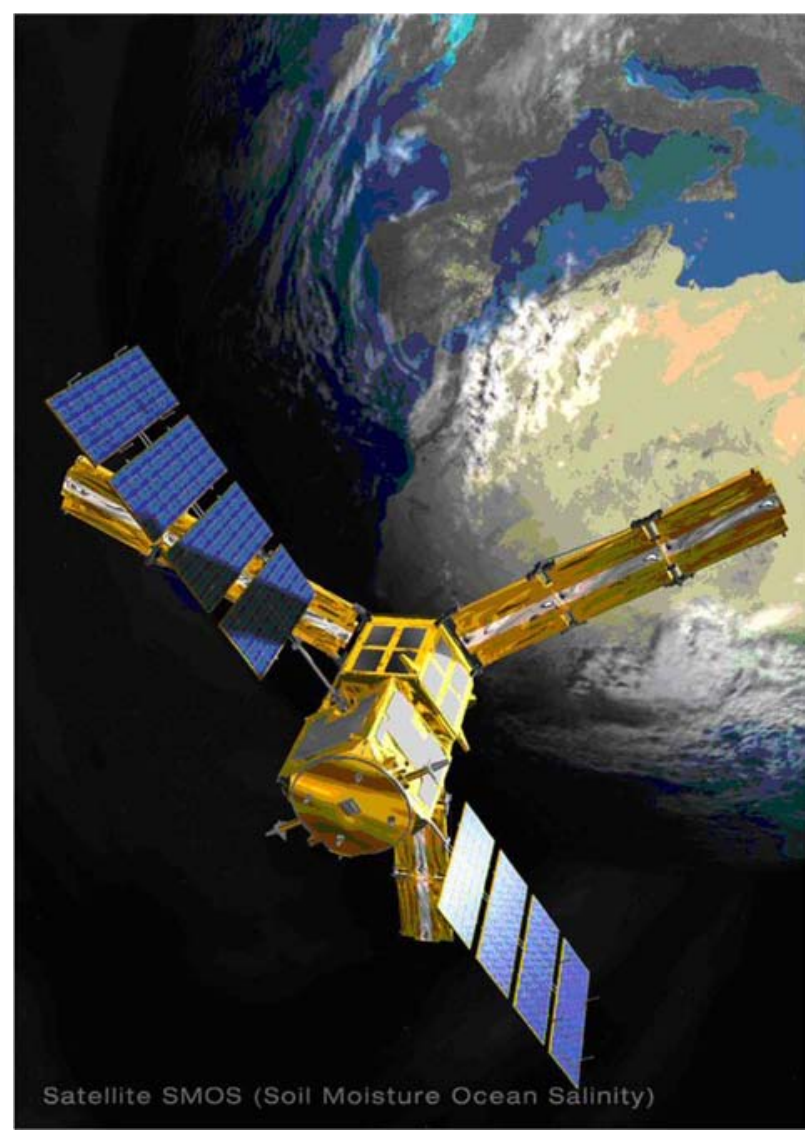

Fig. 1. Artists view of SMOS.

b) Instrument: The result is an instrument with 69 elementary antennas regularly spaced along the arms (0.875 wavelength). The instrument is tilted in an Earthfixed attitude with a constant forward tilt angle of $32.5^{\circ}$ between the instrument boresight and the local nadir, in the flight direction. This ensures an angular coverage of about -10 to +60 . The bus has a yaw-steering angular motion around the local nadir to compensate for the Earth rotation effects on the ground trace of the SMOS images, with an amplitude of about $4^{\circ}$. The steer angle is such that the imaged "hexagon" stands on a base rather than an angle.

The resulting configuration provides at each integration step a full image (about $1000 \times 1200 \mathrm{~km}^{2}$ ) at either two polarizations or full polarization of the Earth's surface [68] (see Fig. 2).

Fig. 3 shows the first image made with the actual SMOS instrument. The average ground resolution is $43 \mathrm{~km}$ over land and the globe is fully imaged twice (ascending and descending orbits) every 3 days at 6 A.M. and 6 P.M. local solar time (equator crossing time). This orbit has the added advantage of enabling good power availability throughout the year (small Sun eclipses in winter) and 


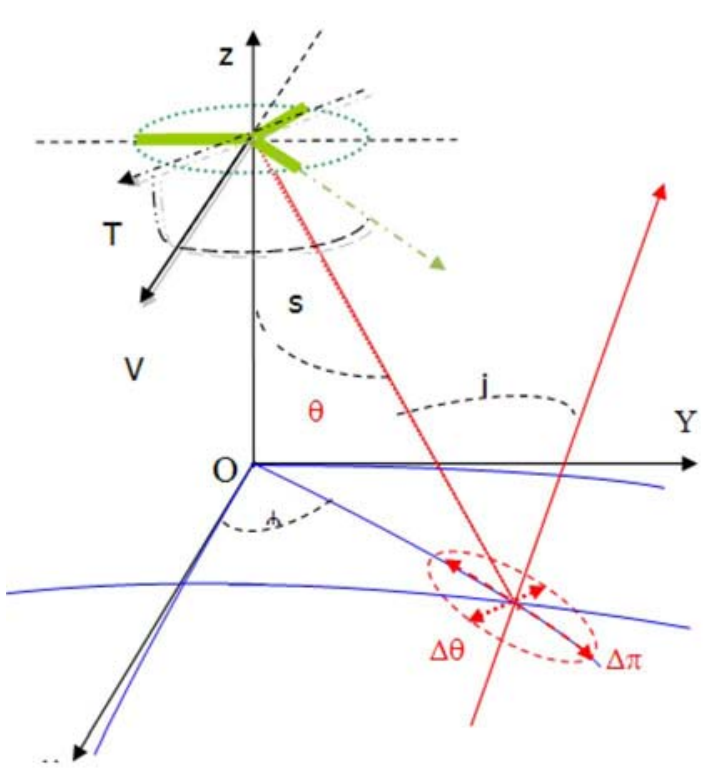

(a)

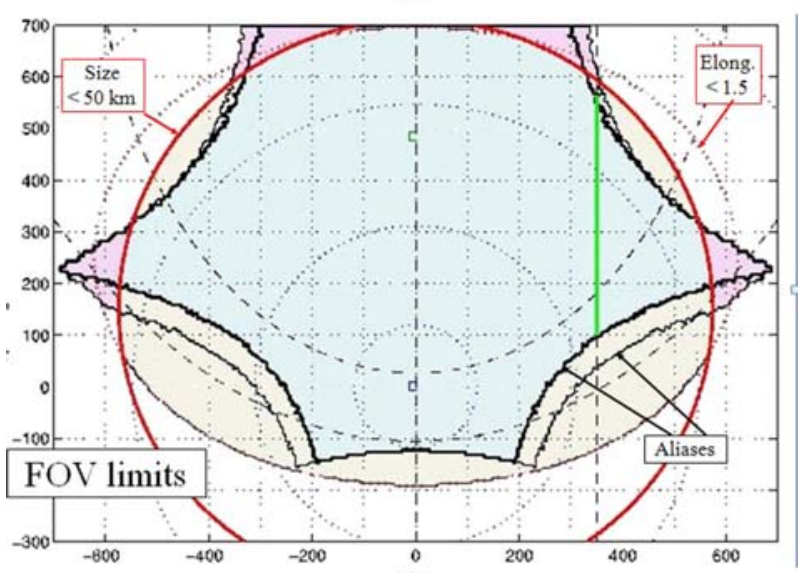

(b)

Fig. 2. (a) Viewing geometry: " $T$ " is the tilt angle and " $\mathrm{S}$ " the steer angle. " $V$ " is the velocity vector while " $i$ " is the incidence angle at ground level. The red ellipse represents a 3-dB pixel at ground level while the blue lines show the Earth curvature. (b) Typical sMOs field of view: The $X$ and $Y$ axes are expressed in term of kilometers at ground level, dashed circles correspond to equiangular measurement, and the different limits of the field of view are indicated (see text).

minimizes thermal variations of the payload in orbit. The orbit is heliosynchronous (about $758 \mathrm{~km}$ ), but with a very low exact repeat (149 days) so that the surface is very rarely seen with exactly the same view angle, avoiding potential biases. As the satellite travels along its orbital path, any point of the surface is imaged from several angles, giving the angular signature of the pixel. The beauty of the concept is that a reasonable spatial resolution is obtained at the cost of a reduced sensitivity. By the same token, the pixels are viewed frequently at different angles and polarizations (see Fig. 4). The angular information is then used to separate the different contributions from soil
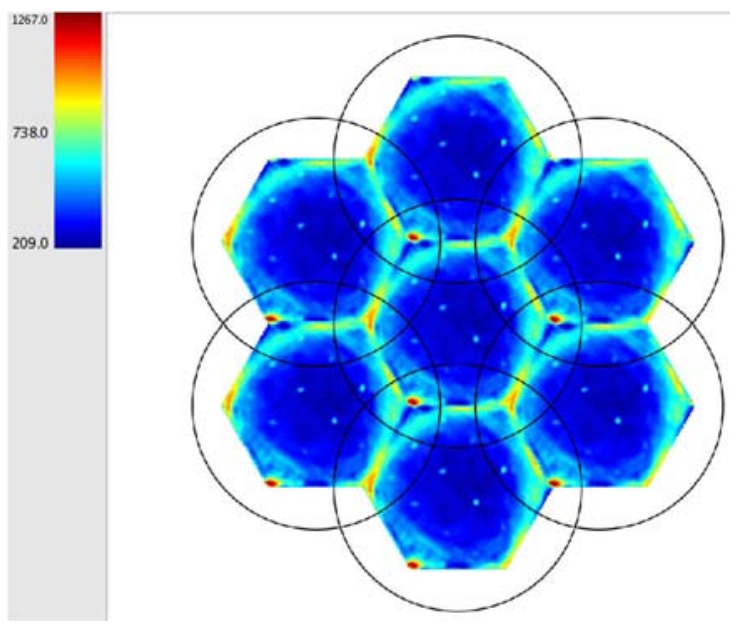

Fig. 3. First image ever made by the SMOS instrument (H pol) during tests in the anechoic chamber (ESA-ESTEC). The picture shows the image and six replicas (aliases) of the chamber's ceiling. Note that the ceiling lights are on. Scale is in Kelvin.

and vegetation to the signal over land [43], [69], and spatially and temporally integrated over the ocean to ensure an improved sensitivity.

\section{B. System Layout}

The SMOS satellite is composed of a platform, based on PROTEUS generic platform built by CNES and Thalès Alenia Space (TAS) and the SMOS payload module built by

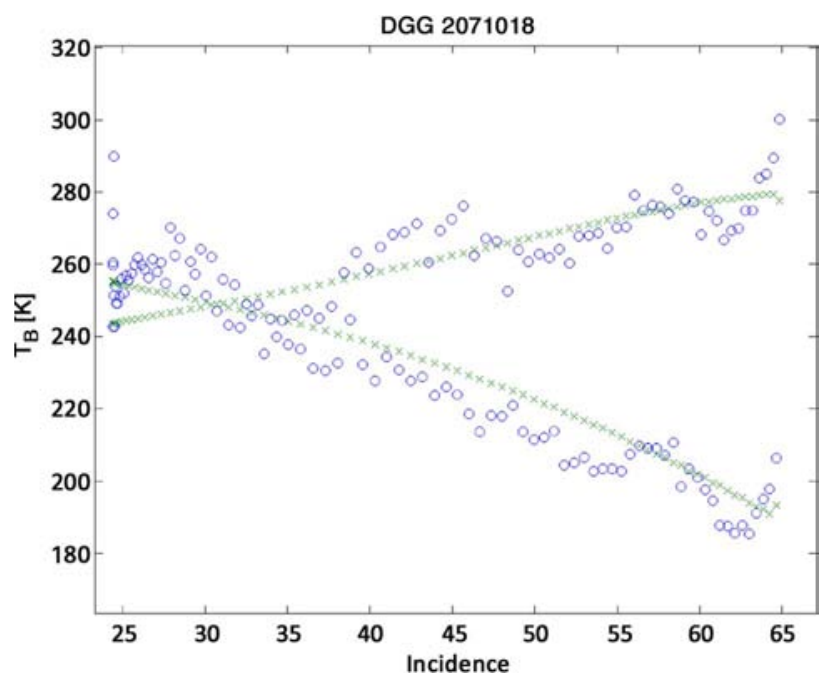

Fig. 4. Typical distribution of brightness temperatures as measured by SMos (simulated) over land. The $X$-axis is the incidence angle in degrees, and the $Y$-axis is the brightness temperatures. The " $O$ " corresponds to simulations, and the " $x$ " to a perfect instrument. Note the measurement noise (worst typical case) and its distribution as a function of view angle. 


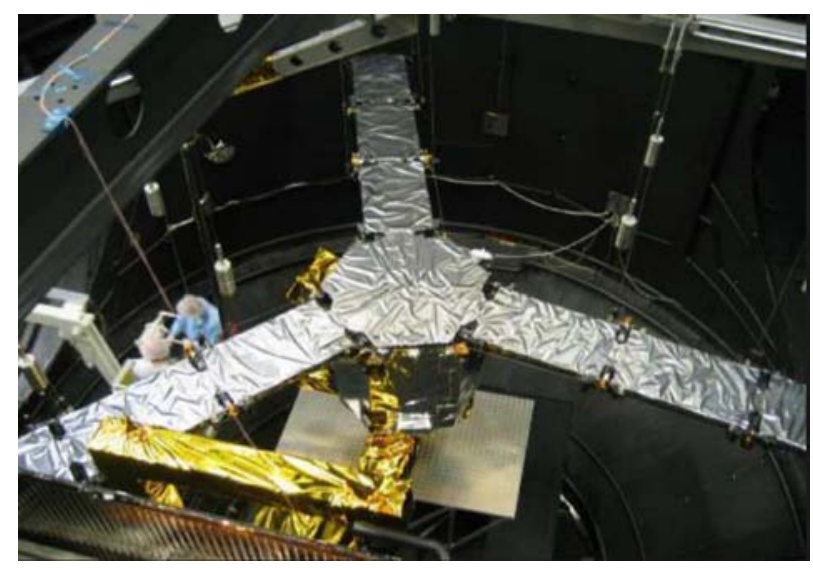

Fig. 5. SMOS payload deployed in the solar simulator at ESTEC. The person with the blue overall gives an idea of the scale.

Construcciones Aeronáuticas Sociedad Anónima-European Aeronautic Defence and Space (CASA-EADS) for European Space Agency (ESA) [70] and is shown in Fig. 5. The system is designed to be able to operate for at least five years. The SMOS satellite was injected into a low-Earth, polar Sun-synchronous orbit (6 A.M./6 P.M.) with a mean altitude of $758 \mathrm{~km}$ on November 2, 2009. The launch vehicle was the Rockot-Breeze KM, operated by Eurockot from the Plesetsk Cosmodrome in Russia.

The SMOS instrument was developed in Madrid, Spain, by EADS-CASA and extensively tested in the ESA and then delivered to Thales Alenia Space in Cannes, France, in mid 2007 for assembly integration and testing. The satellite was thus fully tested and validated. Table 3 gives the performances as measured during tests at ESA-ESTEC and at Thales Alenia Space. The numbers refer to both sea and land surfaces at 150 and $220 \mathrm{~K}$, respectively, for a 1.2-s integration time and at boresight $\left(0^{\circ}\right)$ and at $32^{\circ}$ away from boresight.

\section{Ground Segment}

Architecture: The SMOS ground segment is composed of different interconnected elements.

- The Satellite Operations Ground Segment (SOGS) is in charge of operating, controlling, and monitoring the satellite. It has two elements: the SMOS Command and Control Centre, based on the Proteus generic control center, located in Toulouse, France, and the Telemetry, Tracking and Tele-Command Earth Terminal S-band ground station, insuring bidirectional (telemetry and telecommand) communications with the satellite, which is located in Kiruna, Sweden, and part of the CNES ICONES stations network.

- The Payload Operations Programming Centre (PLPC) is in charge of monitoring, controlling, and programming the operations of SMOS. The PLPC ensures the interfaces and links between SOGS and the Data Processing Ground Segment (DPGS), acquires and monitors all SMOS PLM housekeeping telemetry routed from the satellite to ground via the S-band telemetry channel of the SOGS, and receives and routes the high-level Payload Operations Plan (POP) to the satellite. Finally, the SMOS Data Processing Ground Segment (DPGS) is in charge of acquiring, processing, archiving, and dispatching the SMOS scientific data up to level 2 and associated data generated in-orbit.

The DPGS is composed of the following.

- The SMOS Payload Data Processing Centre (PDPC), where the main function is to process, calibrate, and archive the SMOS scientific data up to level 2 inclusive. The SMOS PDPC includes in particular the Science Data Processing Centre and the Calibration and Expertise Centre.

- $\quad$ The SMOS User Service Centre insuring interfaces and services between the SMOS System and the external users.

The DPGS, including the PDPC, is located in the ESAESAC in Villafranca, Spain, while the User Service is distributed between ESA-ESAC and ESA-ESRIN in Frascati, Italy.

Products: Within the programmatic constraints of the SMOS mission, ESA will generate and deliver data products up to level 2 inclusive. The SMOS data will be nominally processed in the DPGS and several types of products will be made available to the community at large.

Data products for level 3 and level 4 will be produced outside ESA by national centers in France and Spain. For instance, the Centre Aval de Traitement des Données SMOS (CATDS) will be in charge of processing, calibrating, archiving, and dispatching the SMOS scientific data at level 3 and level 4 including geographic maps and special products and image reconstruction. Based on and derived from the level 1 and level 2 products, the data processed by the CATDS will be archived at the CATDS or at the DPGS, and will be distributed to authorized users. A similar center will be operated in Spain-Centro de Producción de datos de nivel 3 y 4 (CP34). SMOS data products noted below will be available from ESA [71], [72].

3) Level 1: The level 1A product comprises calibrated visibilities, i.e., the output of the correlations between receivers prior to applying image reconstruction [73]. Level $1 \mathrm{~A}$ products are basically half-orbits going from one pole to the other. The level 1B product is the output of the image reconstruction of the observations and comprises the Fourier component of the brightness temperature in the antenna polarization reference frame, hence brightness 
Table 3 Table of Measured Performances of SMOS (Courtesy ESA DEIMOS)

\begin{tabular}{|c|c|c|}
\hline System Parameter & $\begin{array}{l}\text { Specified Value } \\
\left(0^{\circ}=\text { bore sight; } 32^{\circ}\right. \\
=\text { edge of } \text { swath })\end{array}$ & $\begin{array}{l}\text { Measured Value } \\
\text { (from tests) }\end{array}$ \\
\hline Systematic Error & $\begin{array}{c}1.5 \mathrm{~K} \mathrm{rms}\left(0^{\circ}\right) 2.5 \mathrm{~K} \\
\mathrm{rms}\left(32^{\circ}\right)\end{array}$ & $\begin{array}{l}0.9 \mathrm{~K} \mathrm{rms} \mathrm{in} \\
\text { alias-free FoV }\end{array}$ \\
\hline $\begin{array}{l}\text { Level-1 SM Radiometric } \\
\text { Sensitivity }(1.2 \mathrm{~s}-220 \mathrm{~K})\end{array}$ & $\begin{array}{c}3.5 \mathrm{~K} \mathrm{rms}\left(0^{\circ}\right) 5.8 \mathrm{~K} \\
\mathrm{rms}\left(32^{\circ}\right)\end{array}$ & $\begin{array}{l}2.23 \mathrm{~K} \mathrm{rms} \\
3.95 \mathrm{~K} \mathrm{rms}\end{array}$ \\
\hline $\begin{array}{c}\text { Level-1 OS Radiometric } \\
\text { Sensitivity }(1.2 \mathrm{~s}-150 \mathrm{~K})\end{array}$ & $\begin{array}{c}2.5 \mathrm{~K} \mathrm{rms}\left(0^{\circ}\right) 4.1 \mathrm{~K} \\
\mathrm{rms}\left(32^{\circ}\right)\end{array}$ & $\begin{array}{l}1.88 \mathrm{~K} \mathrm{rms} \\
3.32 \mathrm{~K} \mathrm{rms}\end{array}$ \\
\hline Stability $(1.2 \mathrm{~s})$ & $4.1 \mathrm{~K} \mathrm{rms}\left(<32^{\circ}\right)$ & $\begin{array}{c}\text { during } 10 \text { days } \\
\text { inside EMC } \\
\text { chamber } 4.03 \mathrm{~K} \\
\text { rms }\end{array}$ \\
\hline Stability (long integration) & $0.03 \mathrm{~K}$ & $<0.02 \mathrm{~K}$ \\
\hline
\end{tabular}

temperatures as measured at instant "t." Level 1B corresponds to one temporal measurement, i.e., the whole field of view-one integration time - and is often called a snapshot as for a camera. The level $1 \mathrm{C}$ product corresponds to a level $1 \mathrm{~B}$ product reorganized with the angular brightness temperatures at the top of the atmosphere grouped together. The product is geolocated in an equalarea grid system (ISEA 4H9-Icosahedral Snyder Equal Area projection). Finally, for ease of visualization, a browse product is built in. It contains only one angular measurement (at $42.5^{\circ}$ incidence angle) and corresponds to what a conical scan instrument may see. The angle was selected so as to cover the whole swath. An example is shown in Fig. 6 with a browse product at satellite level for land.
Two different level $1 \mathrm{C}$ products are generated according to the surface type: one containing only sea and the other only containing land pixels. Fig. 7 gives one of the very first acquisition by SMOS. The image is not calibrated.

4) Level 2: The level 2 soil moisture product contains not only the retrieved soil moisture, but also a series of ancillary data derived from the processing (nadir optical thickness, surface temperature, roughness parameter, dielectric constant, and brightness temperature retrieved at top of atmosphere and at the surface level), with the corresponding uncertainties. As for level $1 \mathrm{C}$, the product is geolocated on the ISEA grid [74]. An example of level 2 is given in Fig. 8, which is the product obtained with SMOS

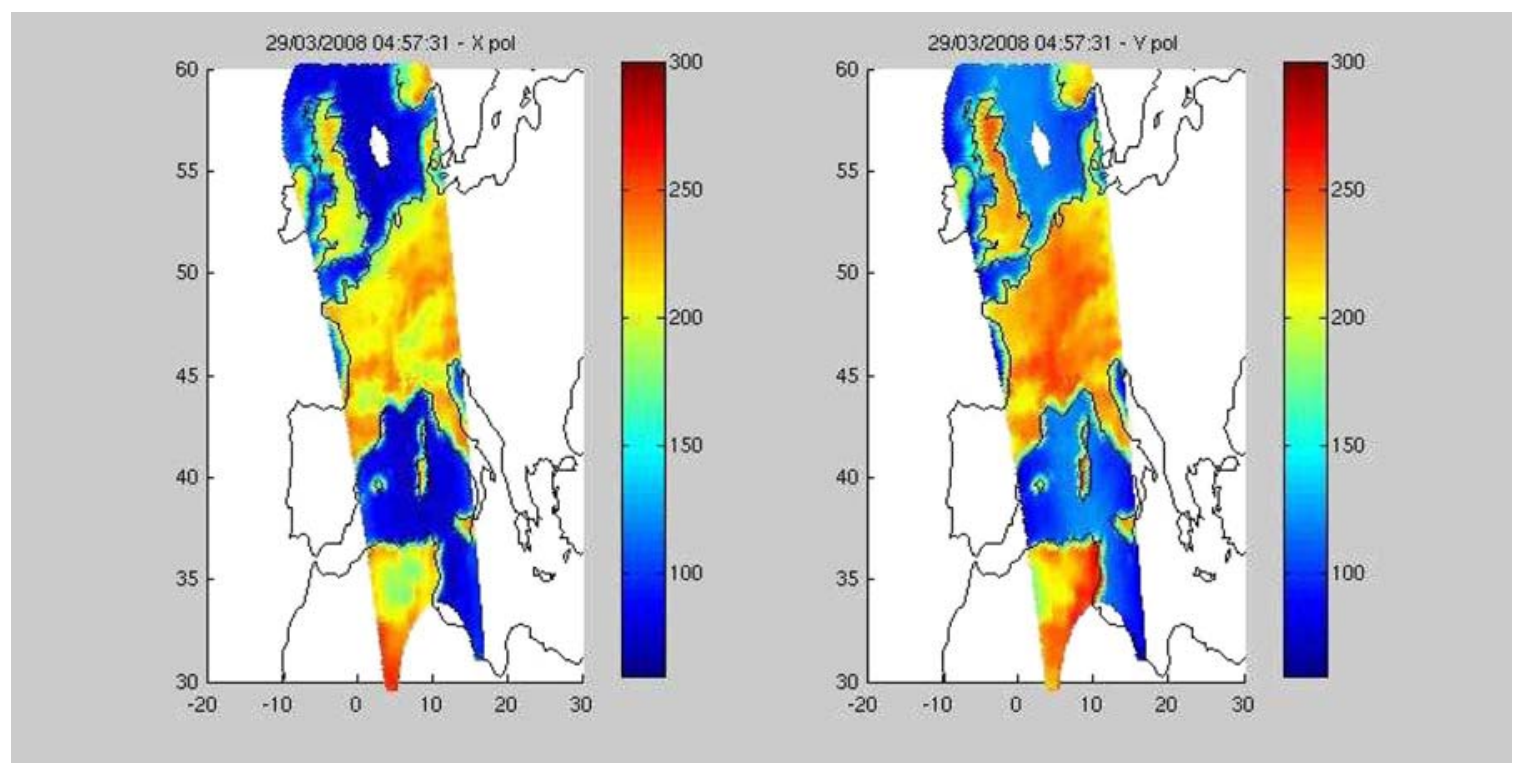

Fig. 6. Simulated orbits over Europe (rehearsal campaign) using SEPSBIO. Browse L1C product: Brightness temperatures at antenna level. Scales are in $\mathrm{K}$. 


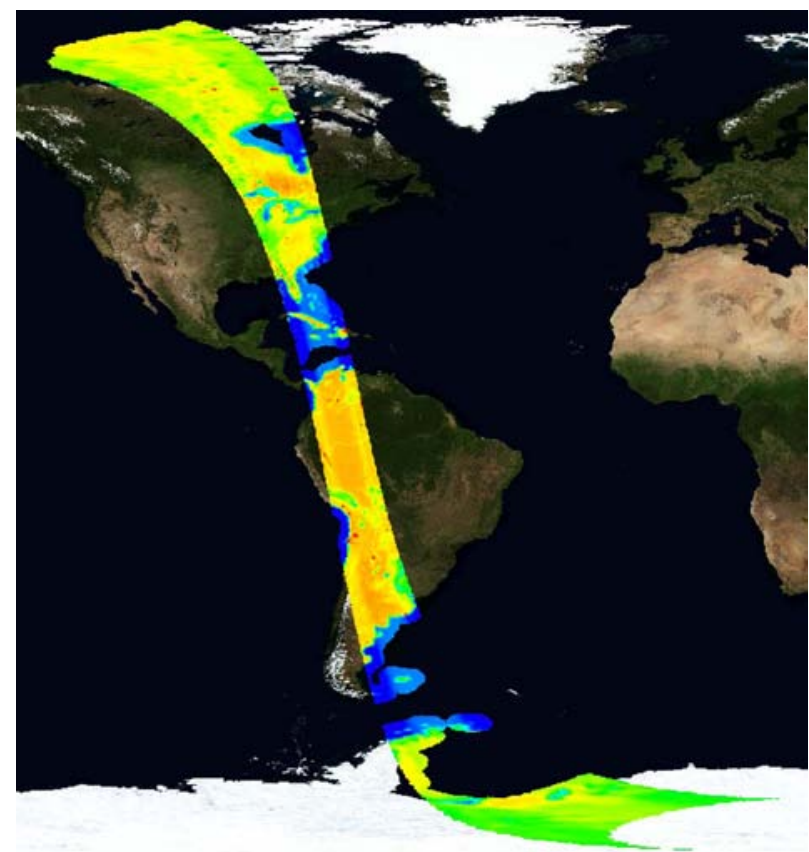

Fig. 7. First SMOS acquisition (December 4, 2009) with preflight calibration and reconstruction parameters. Land level $1 \mathrm{C}$ browse product $\boldsymbol{H}$ pol (at satellite level).

End to end programme Simulator for the BIOsphere (SEPSBIO) (Fig. 6) and processed with the level 2 processor for the rehearsal campaign (SEPSBIO is described in Section VI). The level 2 ocean salinity product contains three different ocean salinity values derived from retrieval algorithms using different assumptions for the surface roughness and the brightness temperature retrieved at the top of atmosphere and on the surface, with the corresponding uncertainties [75]. The level 2 ocean salinity product is geolocated on the ISEA grid.

The level 2 retrievals are based upon the use of a fairly classical inversion approach by minimization. Over the ocean, three different algorithms are currently being investigated; one being empirical. The principle is to take as much angular information as possible after accounting for or eliminating perturbing factors, i.e., the galactic contribution, Faraday rotation, and sea state, and perform spatial temporal averaging. The details can be found in [51] and [75]. Over land, the approach includes a cost minimizing function between the actual angular measurements and the computed brightness temperatures obtained through direct modeling of the surface [43], knowing the surface cover and soil texture. Vegetation cover is estimated directly during retrieval for all points in the narrow swath, where a large number of view angles are available, and by using the previous inversion for the outer part of the swath. The retrieval algorithm is detailed in [74].

5) Near-Real Time Product: One of the goals of the SMOS mission is to provide weather forecast models with soil moisture fields in a timely fashion that corresponds to data made available in the assimilation schemes within three hours of sensing. In SMOS, being an Earth Explorer mission, such a requirement was not deemed as a priority as the concept had yet to be proved. Nevertheless, centers such as Météo France, the European Centre for Medium
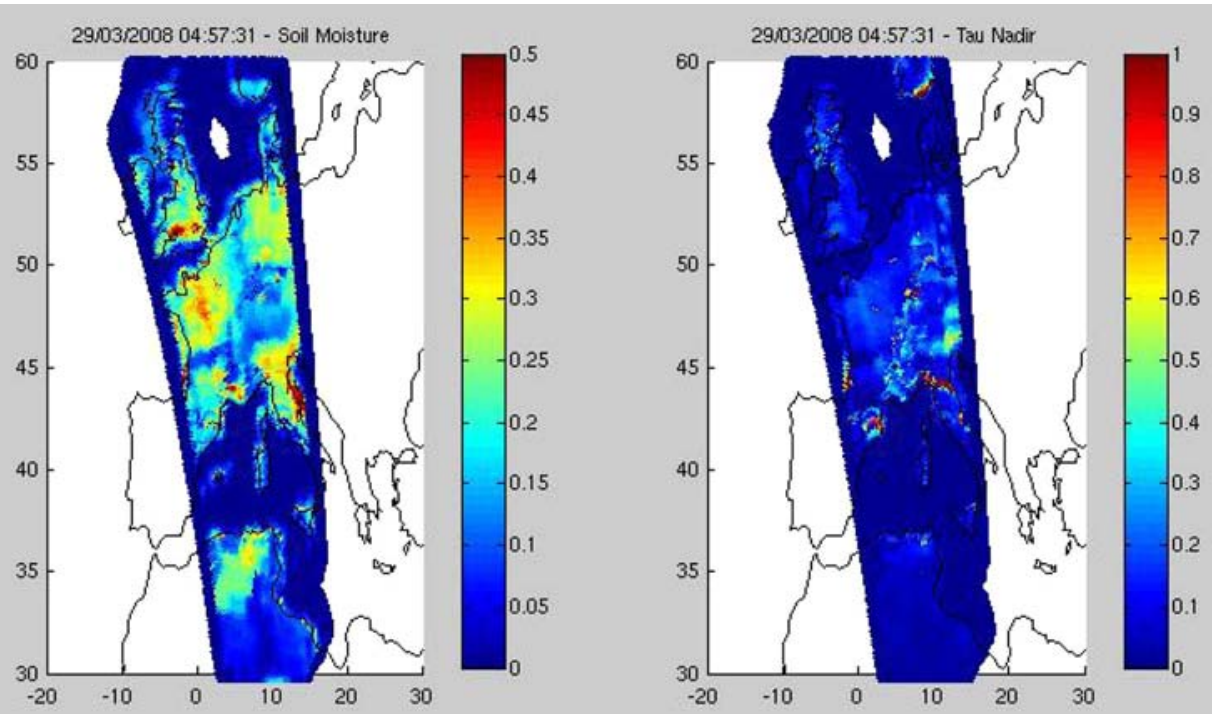

Fig. 8. Level 2 soil moisture and vegetation opacity as retrieved with L2 processor over land during the rehearsal campaign. 
Range Weather Forecasting (ECMWF), the Australian Bureau of Meteorology, and others expressed a strong interest in testing the assimilation of SMOS data. Such requests led to the adaptation of the baseline scenario and resulted in the implementation of a high-latitude receiving station (Svalbard), which will acquire 10-14 orbits per day. The data are to be processed directly so that they can be ingested at ECMWF. It is well understood that the models will require some tuning, but the sooner the data are used the sooner forecasts will benefit from them. The near-real time product, similar to the level $1 \mathrm{C}$ product but adjusted to requirements of operational meteorological agencies such as ECMWF and Meteo France, will be available three hours from sensing. It will contain brightness temperatures at the top of the atmosphere on an ISEA grid with reduced spatial resolution over the ocean (ISEA $4 \mathrm{~h} 8$ instead of $4 \mathrm{~h} 9$ over land).

\section{Caveats}

1) Root Zone Soil Moisture: A big caveat of remote sensing of soil moisture is that currently available direct measurements only penetrate the surface layer. However, for several applications, it is necessary to know the available water in the entire unsaturated zone. Here, the only direct approach that can be currently considered is using even lower frequencies (wavelengths of several meters) so as to reach deeper layers. From a technical point of view, this approach will lead to large footprints (a few hundred kilometers) and will suffer from ionospheric effects, reducing further its attractiveness. Indirect methods, such as assimilation techniques, could be used to model the root zone soil moisture behavior from regular surface measurements and forcing conditions. Such an approach has been validated by using both simulations and ground data, the limitation of which remained linked to the models' performances and to the input data quality [20], [76].

2) Watershed Scale: The other notable limitation of the approach, after the partial probing of the unsaturated zone, is the spatial resolution. Hydrological applications require soil moisture to be resolved at a much higher spatial resolution while maintaining a high temporal sampling frequency. From space, such approach would be too complex. A promising approach, the "disaggregation" techniques, will make use of external information to redistribute the area's average soil moisture within the pixel. A number of recent studies have demonstrated the validity of such approach with simulated SMOS data [77], [78], and are now ready for validation with the real thing.

\section{3) Remaining issues}

a) Land: Over land, not all problems have been solved; there are a number of outstanding issues which will require attention before an accurate and global soil moisture product is routinely available. RFI can be a serious issue of major concern. The frequency band selected for SMOS is a protected band and the measurements should be free of any interference. As a matter of added precaution the actual bandwidth used for SMOS was reduced by $6 \mathrm{MHz}$ to limit the influence of emissions in neighboring bands at the cost of the sensitivity. The main sources of RFI may be linked in several cases to either military installations, or not properly filtered harmonics of 700-MHz UHF television bands or equivalent mobile phone emitters. The early SMOS measurements indicated the presence of very strong RFI sources (see the red "dots" in Fig. 7 and note that some areas of the world are much more perturbed).

The issues identified above are currently being tackled as can be seen from below. However, as long as the real data (SMOS or any other) are not available, definitive conclusions and/or solutions will not be available and unexpected issues might arise.

Currently, the following issues are well identified over land, the most stringent being the subpixel heterogeneity where surface types will have very significant differences in radiometric behavior.

The presence of free water within the pixel, for instance, has to be very accurately known (better than 2\%) to reach the overall accuracy of $0.04 \mathrm{~m}^{3} / \mathrm{m}^{3}$ in soil moisture, as a very simple calculation can show. However, water bodies are variable as a function of season and weather conditions, let alone human activity.

At L-band, vegetation is not totally transparent, and when the integrated water content is above $4-5 \mathrm{~kg} /{ }^{2}$, soil moisture retrievals will be difficult and approximate, i.e., over forested canopies.

It should be noted that recent studies have showed that the main L-band contribution of forested canopy was branches, and that these do not evolve rapidly [79], [80]. Litter on the ground can behave as a black body, masking strongly the soil's signal [81].

During rain events, water interception by the canopy might artificially increase the apparent vegetation's water content [82].

Topography will induce an altered angular behavior; snow and frozen soils will induce different signals which, if not accounted for, will produce wrong estimates [83].

Urban areas and rocks are not fully assessed in terms of emissivity.

b) Oceans: Over the oceans, a number of wellidentified challenges remain [51].

The main challenge is the high radiometric sensitivity needed for the retrieval of ocean salinity, which puts stringent requirements on the instrument, but also on the correction needed to reduce all the perturbing factors in this complex instrument.

From a modeling point of view, the main unknown is the impact of sea state which is still not fully satisfactorily 
modeled and the relation between surface salinity and salinity at depth (where it is generally measured).

Stability of the instrument and access to values in coastal areas where the lobe intercepts a surface with a high brightness temperature compared to the ocean surface will be a challenge.

At level 3, the impact of inaccurate auxiliary data (i.e., ECMWF data), in particular when correlated to sea surface temperature and winds in frontal zones, on the spatiotemporal averaging, still needs to be better understood.

c) Summary: In conclusion, good retrieval will require knowledge of the surface cover and state, and the quality of the retrievals will be closely linked to the quality of the input data.

It must be noted that an interferometric systems such as SMOS will bring inherent complexity, in particular in image reconstruction which remains an area where actual data will probably lead to significant progresses.

\section{E. Calibration}

Calibration for SMOS is challenging as it is twofold. On the one hand, as the absolute temperature is given by a radiometer with a very large field of view (around $70^{\circ}$ angular aperture at $3 \mathrm{~dB}$; called the noise injection radiometer for SMOS), it requires a classical calibration approach. The calibration has nevertheless to be very accurate and stable (SSS retrievals) which is challenging due to the large field of view and the impossibility to have a black body in front of the antenna. On the other hand, the interferometer itself has to be calibrated which requires novel approaches. To cover these points several approaches have been taken as described in [84], which will be fine tuned during the commissioning phase. The internal calibration is performed by monitoring all the key elements regularly using different noise injection sources, and every month a complete orbit is dedicated to monitor its orbital behavior in detail. The local oscillators are subject to phase changes as a function of temperatures, and are monitored at regular interval. To monitor the orbital harmonic behavior of the sensor, on a regular basis, short calibrations will be performed in such a way as to scan the orbital variation roughly every week with something like ten samples a day. The approach foreseen to establish the routine calibration plan is to accumulate as much information as possible on the instrument behavior during the commissioning phase, so as to model the orbital behavior of the system as a whole and to optimize the routine calibration procedures.

The noise injection radiometers (three) provide the overall brightness temperature and must be very well calibrated. Their calibration is based on classical on-board methods, implemented in complex timelines defining the different operating modes of the instrument [85]. Initial absolute radiometric comparisons will be performed with the interferometer looking at well-known bright point sources (typically strong sources in the galaxy (Milky Way) such as Cygnus X-20 or Cassiopeia, as well as the galactic pole, to perform the flat target transformation correction. To perform such activity, the satellite will have to be pointing "up" using slew maneuvers in the orbital plane for which two attitude submodes exist.

- Inertial attitude, where the instrument boresight is controlled and pointed to a constant inertial direction.

- Earth-fixed attitude, where the instrument boresight is controlled and pointed to a constant pitch (or tilt). A particular case of this mode is when the satellite is oriented and maintained in the zenith direction, allowing the payload to image the deep sky while keeping the Earth outside the main lobe of the antenna patterns.

Both external calibration modes allow calibration of the instrument using different celestial areas for a specified duration of up to $30 \mathrm{~min}$, with a pointing stability of less than $0.3^{\circ}$. The complete duration of the external calibration modes, including slews and returning to nominal measurement attitude, is less than one orbital period, i.e., less than $100 \mathrm{~min}$. However, these calibration techniques will suffer from the following imperfections: 1) during the maneuvers, the antenna back lobes will be sweeping the earth surface and will therefore have to be performed while flying over oceans, and 2) the thermal equilibrium of the whole satellite will be modified. First in flight results seem to show that over 100 min the thermal regulation of the payload is able to cope with the different thermal loading. Vicarious calibration will be performed using stable ground targets, with all the inherent issues linked to this; the goals being to verify the calibration curve over as wide brightness temperatures range as possible, i.e., stable ocean, Antarctica, dry deserts).

\section{F. Geolocation}

Very early in the project, it was identified that small errors in the ratio of land to water surface cover would lead to very wrong retrievals. Even if one assumes that the locations of water bodies are well known, their exact location in the footprint will also have to be known precisely to properly account for the antenna response. It was shown that typically, over land, a $2 \%$ error in water body contribution could lead to a $0.03-\mathrm{m}^{3} / \mathrm{m}^{3}$ error in soil moisture retrieval. This is not compatible with the $0.04-\mathrm{m}^{3} / \mathrm{m}^{3}$ target in particular when considering other potential sources of error. It was thus considered that, so as to ensure the mission requirements, a geolocation accuracy of $400 \mathrm{~m}$ was required. This very stringent target was studied in depth by the project, where it was found that this requirement, although not fully fulfilled, was within reach (computations in worse case give $700 \mathrm{~m}$ at one sigma). An estimation of the pointing biases will be performed by analyzing ascending and descending orbits over a long and almost linear coastline (Madagascar) [86]. 


\section{G. Launch Scenario (Commissioning Phase)}

Just after launch, SMOS will undergo a six month commissioning phase. During this period the whole system will be thoroughly tested and, as with any novel technique/ instrument, a number of issues will have to be addressed, and the system tuned. During the first period, the PROTEUS platform will be commissioned (about 2.5 weeks). After, the instrument will be switched on and the different operating modes will be tested (calibration and dual and full polarization modes) while the geolocation biases will be assessed. From this point on, a series of calibration schemes will be operated. The goals are both to study the stability and behavior of the instrument in orbit as well as optimize the calibration sequences (type and frequency) so as to ensure meeting the requirements with minimum science data loss. At the same time, the different steps for image reconstruction (G Matrix, flat target transformation data, etc.) will be acquired so that the data generation is operational and tuned. The plans are to finish these tests within 12 weeks after launch. Then, the second phase of the commissioning phase will be initiated. This phase will have an objective to select which mode of operation, dual or full polarization, SMOS will be operated in during exploitation. To achieve these goals, the instrument will operate alternatively in dual and full polarization (one week each) for the remaining 14 weeks. This will enable the Expert Support Laboratories (ESL) to produce a first product validation accuracy estimate to support such a decision. In parallel, a number of ground experiments will be carried out to initiate the calibration and validation $(\mathrm{Cal} / \mathrm{Val})$ procedure. If all goes well, SMOS will end the commissioning phase six months after launch (early May 2010) and start routine operations as of then.

\section{SMOS VALIDATION ACTIVITIES}

Historically, no space-borne L-band instrument or similar soil moisture retrieval algorithms were available to prepare the SMOS mission. This is the consequence of being first and has to be accepted. The approach taken to validate the measurement approaches and associated algorithms was to make extensive use of ground data (radiometers) and aircraft data (see Fig. 9) in conjunction with an end-to-end simulator SEPSBIO from which the SMOS mission outputs were derived. SEPSBIO simulates the surface emission at a high resolution (typically 1-4 km) using state of the art emissivity models for land and sea surfaces, using validated surface characteristics. The simulator also accounts for external contributions such as galactic and sun reflections and direct signals. This geophysical signal is propagated to the instrument (traveling along a modeled orbit) using the instrument simulator (SEPS-GS). SEPS-GS is configured with measured instrument characteristics, and will compute the instrument signal output (instrument source packets) which is further processed to level 1 and level 2

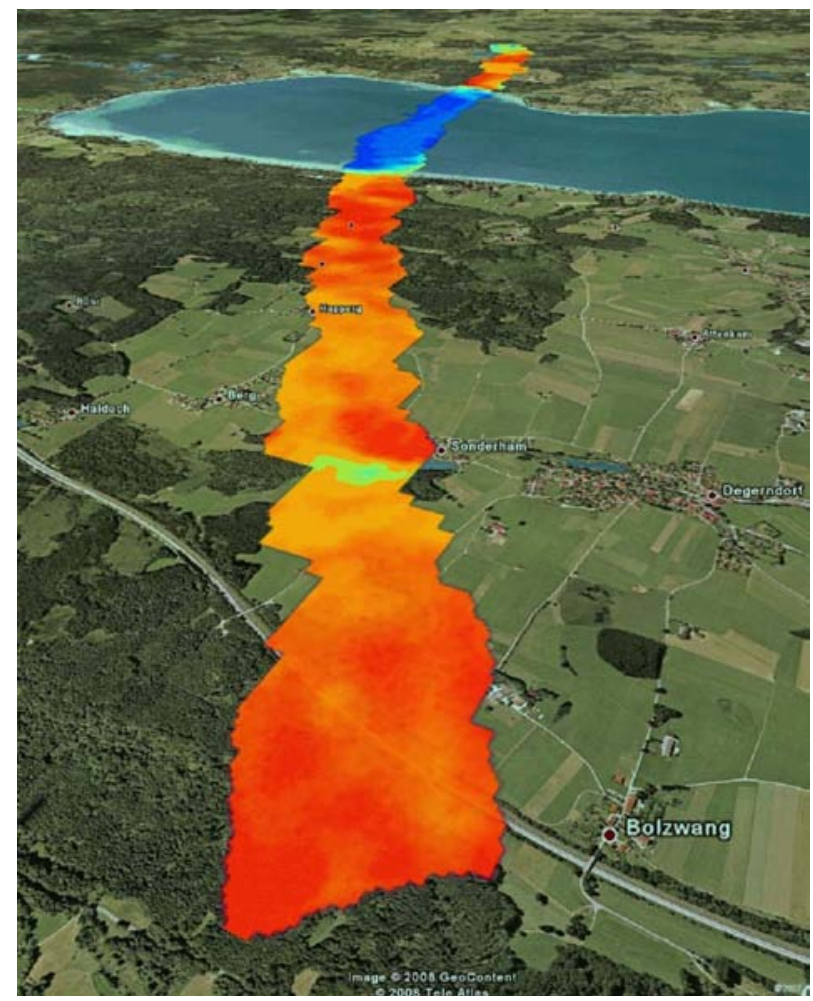

Fig. 9. Scene acquired during the rehearsal campaign over Germany by the HUT 2D SMOS demonstrator (courtesy TKK).

using the SMOS processors. The simulations provided in this paper were all produced with SEPSBIO.

The SMOS Validation and Retrieval Team (SVRT) was established by ESA by selecting the projects proposed in response to the SMOS calibration and validation tender released in 2005. This team will work in close collaboration with the level 2 ESL being involved in the development of the soil moisture and ocean salinity data products and retrieval algorithms. For the validation of soil moisture, the ESA activities will focus on two main sites: the Valencia Anchor Station and the Upper Danube watershed. These sites will be equipped, manned, and monitored throughout the SMOS mission. In order to generate quality "match-up" between ground measurements and SMOS products, it is necessary to compute estimates of soil moisture corresponding to the SMOS pixel size. This will be achieved by use of a dense network of soil moisture probes and atmospheric forcing measurements, coupled to a good knowledge of land use and soils types. All these ingredients will be included in a SVAT scheme would will produce spatially distributed soil moisture maps covering the validation site, and this continuously. In parallel, so as to have a reference brightness temperature, an L band field radiometer will continuously monitor the most representative area of the whole validation site. Such a scheme should enable us to have a good 
idea of soil moisture and (with a radiative transfer code and the radiometer) of brightness temperature whenever SMOS overpasses these areas. A close collaboration is foreseen with the NASA Aquarius and SMAP teams for, respectively, the validation of ocean salinity and soil moisture products. For an overview on the SMOS validation activities, see [87]. Considering the winter launch date for SMOS, strong collaborations have been established with Melbourne University, Australia, to allow the project access to a range of soil moisture and vegetation water content cycle, not available in the northern hemisphere during the six month commissioning phase starting in November 2009.

A number of campaigns (Cosmos [88], [89], WISE [90], LOSAC [90], EUROSTARRS [91]) have been performed to investigate uncertainties in the soil moisture and ocean salinity retrieval. In complement to the two main sites mentioned above, several sites are being monitored continuously, either to check stability (such as Dome Concordia Experiment in Antarctica (DOMEX) [92], [93]) or to investigate diurnal/seasonal variability of the signal and to validate the retrieval algorithms (see, for instance, SMOSREX [94]). The major aspects investigated with regard to soil moisture are the influence of different vegetation types and their seasonal variability, as well as the influence of surface roughness and soil types. For ocean salinity, the main issue is the impact of sea surface state on the polarimetric radiometric signal. While a number of validation sites are being instrumented in preparation for validation activities for SMOS, and probably Aquarius and/or SMAP later, several sites will be up and running during the SMOS commissioning phase, i.e., the MoistureMap site in Australia, the HOBE site in Denmark, the Mali site in Western Africa, the SMOSMania site in south west France, just to name a few. Each site is associated to a specific ecoclimate and/or vegetation type. Finally, it should be stressed that a number of large campaigns will take place during the SMOS commissioning phase, i.e., MoistureMap in Australia in winter 2009, and ESA and CNES campaigns in Europe in spring 2010; the goal of the European campaigns being to cover as many validation sites as possible, with both intensive field measurements and aircraft overpasses. In Europe, a rehearsal campaign was organized in April 2008 so as to exercise the procedure and validate the approach.

Over the ocean, the Cal/Val activities will take advantage of all existing SSS measurements. In addition, in order to better document temporal variability and vertical stratification, about 100 drifting buoys will be deployed by the SMOS European team. In addition to these, the European deployment strategy in preparation for SMOS includes the following: 1) the GLOSCAL French project will deploy 30 drifters in North Atlantic and the equatorial band (with the main focus in the equatorial Atlantic and equatorial Pacific, and two deployments planned in the equatorial Indian); 2) the German group will deploy 25 in polar seas and equatorial Pacific; and 3) the Spanish group will deploy 40 in the subtropical Atlantic, Southern Ocean, and Mediterranean Sea in 2010-2011.

\section{CONCLUSION AND PERSPECTIVES}

Soil moisture and SSS are two critical variables for which global measurements have been long sought after. Though well identified, there were so few measurements that global circulation models only made limited use of them. However, after many unsuccessful attempts, a real soil moisture and ocean salinity mission, SMOS, is now in space, which should finally enable the community to have access to global fields of soil moisture, and together with ARGO, insight into global ocean salinity distribution.

SMOS is not the first L-band radiometer in space, and will undoubtedly not be the last. The S-194 instrument on the Skylab satellite in 1973-1974 provided the first demonstration of the sensitivity of an L-band radiometer to sea surface salinity and soil moisture. The Skylab experiment conclusively demonstrated the value of L-band radiometer measurements. In spite of the short measurement time span and very low spatial resolution, it proved to be able to deliver useful soil moisture fields.

Until fully commissioned and operational, the SMOS concept still has to be proven. Nonetheless, the successful launch and early performance indications give confidence that the operational SMOS follow-on mission concept currently being studied may well be realized in the near future. The idea is to use the same basic concept with the philosophy to focus on improving things (i.e., local oscillator temperature monitoring, more antennas in the center part of the hub, etc.) so as to improve both sensitivity and stability, without dramatically changing the configuration. The SMOS follow-on mission could then be exploited for operational oceanography and weather forecasting.

In spite of SMOS answering some fundamental scientific questions, it still does not fulfil all existing needs, and ways forward must still be sought to address these. Over land, the most important priority is probably to improve the spatial resolution. In this area, the SMOS concept is close to an optimum, and while increasing the arm's length will improve the spatial resolution, it would also degrade significantly the sensitivity to the point where it would not be useful anymore. Therefore, a new concept SMOS-NEXT has been developed to realize an instrument satisfying all the SMOS requirements but with a much improved spatial resolution (ten times better) [95]. Over oceans, the main limitation is linked to sensitivity and the need for correction of perturbing factors. These two can be overcome by using a new instrument design and/or using other frequencies and active systems as done for Aquarius. To test those options we will use existing collocated sensor data [Advanced SCATterometer (ASCAT) and AMSR-E] when SMOS is operating. This might lead to addressing 
the cryosphere as well, another key element in the global water and energy budget of the planet.

In addition to SMOS, the Aquarius/SAC-D [62] and SMAP missions [63] are to be launched either in the very near future (Aquarius) or in the 2015-2020 time frame (SMAP). Hopefully, these three missions will overlap in time such as to enable intercalibration and intercomparison of their respective data. This will help in building a longer L-band brightness temperature fundamental climate data record, as well as new seamless time series of the essential climate variables (ECV) soil moisture and ocean surface salinity.

It was stated in the SMOS proposal that the concept, though challenging, would open a new field with new measurements - soil moisture-made with a new type of sensors, paving the way for operational monitoring of water in soils. With the recent launch of the SMOS mission, the first step is taken, opening a whole avenue of scientific challenges, and making the long awaited tool for water resources and water cycle monitoring a closer possibility, with in its wake even more challenging concepts such as SMOS NEXT [95].

\section{Acknowledgment}

The authors would like to thank all the contributors to the mission from all over the world. The contributions came obviously from the science teams but also from the technical teams at Agencies (ESA and CNES) and in the Industry (mainly CASA EADS, Thales Alenia Space, and Eurockot, but also many others). The French contribution was supported also by the national program TOSCA. The authors would like to thank H. Rider for her support during editing of the final text. They would also like to thank the reviewers for their time and very useful comments which greatly improved this paper.

\section{REFERENCES}

[1] Y. H. Kerr, P. Waldteufel, J. P. Wigneron, J. M. Martinuzzi, J. Font, and M. Berger, "Soil moisture retrieval from space: The Soil Moisture and Ocean Salinity (SMOS) mission," IEEE Trans. Geosci. Remote Sens. vol. 39, no. 8, pp. 1729-1735, Aug. 2001.

[2] W. Wagner, G. Bloschl, P. Pampaloni, J. C. Calvet, B. Bizzarri, J. P. Wigneron, and Y. Kerr, "Operational readiness of microwave remote sensing of soil moisture for hydrologic applications," Nordic Hydrol., vol. 38, pp. 1-20, 2007.

[3] G. S. E. Lagerloef, C. T. Swift, and D. M. Le Vine, "Sea surface salinity: The next remote sensing challenge," Oceanography, vol. 8, pp. 44-50, 1995.

[4] R. M. Lerner and J. P. Hollinger, "Analysis of $1.4 \mathrm{GHz}$ radiometric measurements from Skylab," Remote Sens. Environ., vol. 6, pp. 251-269, 1977.

[5] Y. H. Kerr, "Soil moisture from space: Where are we?" Hydrogeol. J., vol. 15, pp. 117-120, 2007.

[6] A. C. M. Beljaars, P. Viterbo, M. J. Miller, and A. K. Betts, "The anomalous rainfall over the United States during July 1993: Sensitivity to land surface parameterization and soil moisture," Mon. Weather Rev., vol. 124, pp. 362-383, 1996.

[7] R. D. Koster, P. A. Dirmeyer, Z. C. Guo, G. Bonan, E. Chan, P. Cox, C. T. Gordon, S. Kanae, E. Kowalczyk, D. Lawrence, P. Liu, C. H. Lu, S. Malyshev, B. McAvaney, K. Mitchell, D. Mocko, O. Taikan, K. Oleson, A. Pitman, Y. C. Sud, C. M. Taylor, D. Verseghy, R. Vasic, Y. K. Xue, and T. Yamada, "Regions of strong coupling between soil moisture and precipitation," Science, vol. 305, pp. 1138-1140, 2004.

[8] S. I. Seneviratne, R. D. Koster, Z. Guo, P. A. Dirmeyer, E. Kowalczyk, D. Lawrence, P. Liu, C.-H. Lu, D. Mocko, K. W. Oleson, and D. Verseghy, "Soil moisture memory in AGCM simulations: Analysis of 15 Global Land-Atmosphere Coupling Experiment (GLACE) data," J. Hydrometeorol., vol. 7, pp. 1090-1112, 2006

[9] G. Lagerloef, "Satellite remote sensing: Salinity measurements," in Encyclopedia of Ocean Sciences. New York: Academic, 2000.
[10] G. S. E. Lagerloef, "Satellite Measurements of salinity," in Encyclopedia of Ocean Sciences, S. T. J. Steele and K. Turekian, Eds. London, U.K.: Academic, 2001, pp. 2511-2516.

[11] D. Entekhabi, I. Rodriguez-Iturbe, and F. Castelli, "Mutual interaction of soil moisture state and atmospheric processes," J. Hydrol., vol. 184, pp. 3-17, 1996.

[12] R. W. Schmitt, "Salinity and the global water cycle, 21, 12-19," Oceanography, vol. 21, pp. 12-19, 2008.

[13] T. J. Schmugge, W. P. Kustas, J. C. Ritchie, T. J. Jackson, and A. Rango, "Remote sensing in hydrology," Adv. Water. Resour., vol. 25, pp. 1367-1385, 2002.

[14] D. M. Le Vine, M. Kao, A. B. Tanner C. T. Swift, and A. Griffis, "Initial results in the development of a synthetic aperture microwave radiometer," IEEE Trans. Geosci. Remote Sens., vol. 28, no. 4, pp. 614-619, Jul. 1990.

[15] C. S. Ruf, C. T. Swift, A. B. Tanner, and D. M. Le Vine, "Interferometric synthetic aperture microwave radiometry for remote sensing of the earth," IEEE Trans. Geosci. Remote Sens., vol. 26, no. 5, pp. 597-611, Sep. 1988.

[16] P. Thibaut, Y. H. Kerr, B. Le Stradic, J. C. Magnan, M. Avignon, and F. Castanie, "Generation of a high resolution microwave brightness. Temperature map for assessing aperture synthesis radiometer performances," presented at the IEEE Int. Geosci. Remote Sens. Symp., Washington, DC, May 1990, pp. 1593-1596.

[17] Y. H. Kerr, "RAMSES: Proposition de mission spatiale sur mini satellite au colloque de prospective du CNES (TAOB)," CESBIO, Toulouse, France, Proposal November 1997.

[18] Y. H. Kerr, "The SMOS mission: MIRAS on RAMSES. A proposal to the call for Earth explorer opportunity mission," CESBIO, Toulouse, France, Proposal 30/11/1998.

[19] M. J. Escorihuela, Y. H. Kerr, P. de Rosnay, K. Saleh, J. P. Wigneron, and J. C. Calvet, "Effects of dew on the radiometric signal of a grass field at L-band," IEEE Geosci. Remote Sens. Lett., vol. 6, no. 1, pp. 67-71, Jan. 2009.

[20] G. Balsamo, J. F. Mahfouf, S. Belair, and G. Deblonde, "A land data assimilation system for soil moisture and temperature: An information content study," J. Hydrometeorol., vol. 8, pp. 1225-1242, 2007.

[21] P. A. Dirmeyer and K. L. Brubaker, "Contrasting evaporative moisture sources during the drought of 1988 and the flood of 1993," J. Geophys. Res.-Atmos., vol. 104, pp. 19 383-19 397, 1999.

[22] H. Douville, "Influence of soil moisture on the Asian and African monsoons. Part II: Interannual variability," J. Climate, vol. 15 , pp. 701-720, 2002.

[23] M. Drusch, "Initializing numerical weather prediction models with satellite-derived surface soil moisture: Data assimilation experiments with ECMWF's integrated forecast system and the TMI soil moisture data set," J. Geophys. Res.-Atmos., vol. 112, 2007.

[24] J. Johannessen, C. L. Provost, H. Drange, M. Srokosz, P. Woodworth, P. Schlüssel, P. L. Grand, Y. Kerr, D. Wingham, and H. Rebhan, "Observing the ocean from space: Emerging capabilities in Europe," in Observing the Oceans in the 21st Century, C. J. K. A. N. R. Smith, Ed. Melbourne, Australia: GODAE Project Office and Bureau of Meteorology, 2002, pp. 198-208.

[25] S. C. Riser, L. Ren, and A. Wong, "Salinity in ARGO," Oceanography, vol. 21, pp. 57-67, 2008.

[26] G. S. E. Lagerloef, J. Boutin, X. Carton, Y. Chao, T. Delcroix, J. Font, J. Lilly, N. Reul, R. Schmitt, S. Riser, and F. Wentz, "Resolving the global surface salinity field and variations by integrating satellite and in situ observations," Community White Paper, 2009.

[27] C. Henocq, J. Boutin, F. Petitcolin, G. Reverdin, S. Arnault, and P. Lattes, "Vertical variability of near-surface salinity in the tropics: Consequences for L-band radiometer calibration and validation," J. Atmos. Ocean. Technol., vol. 27, no. 1, pp. 192-209, Jan. 2010.

[28] G. Lagerloef and T. Delcroix, "Sea surface salinity; a regional case study for the tropical Pacific," in Observing the Oceans in the 21st Century; A Strategy for Global Observations, C. K. A. N. Smith, Ed. Melbourne, Australia: GODAE Project Office, Bureau of Meteorology, 2001, p. 604.

[29] C. A. Paulson and G. S. E. Lagerloef, "Fresh surface lenses caused by heavy rain over the 
Western Pacific warm pool during TOGA COARE," Eos. Trans. AGU, vol. 74, p. 125, 1993.

[30] R. Lukas and E. Lindstrom, "The mixed layer of the western equatorial Pacific ocean," J. Geophys. Res., vol. 96, pp. 3343-3357, 1991.

[31] A. Kortzinger, "A significant $\mathrm{CO}_{2}$ sink in the tropical Atlantic Ocean associated with the Amazon River plume," Geophys. Res. Lett., vol. 30 , no. 24 , p. 2287 , DOI: $10.1029 /$ 2003GL018841.

[32] N. Reul, S. Saux-Picart, B. Chapron, D. Vandemark, J. Tournadre, and J. Salisbury, "Demonstration of ocean surface salinity microwave measurements from space using AMSR-E data over the Amazon plume," Geophys. Res. Lett., vol. 36, 2009, DOI: $10.1029 / 2009$ GL038860.

[33] J. P. Wigneron, P. Ferrazzoli, J. C. Calvet, Y. H. Kerr, and P. Bertuzzi, "A parametric study on passive and active microwave observations over a soybean crop," IEEE Trans. Geosci. Remote Sens., vol. 37, no. 6, pp. 2728-2733, Nov. 1999.

[34] M. S. Moran, D. C. Hymer, J. G. Qi, and Y. Kerr, "Comparison of ERS-2 SAR and Landsat TM imagery for monitoring agricultural crop and soil conditions," Remote Sens. Environ., vol. 79, pp. 243-252, 2002.

[35] R. D. Magagi and Y. H. Kerr, "Retrieval of soil moisture and vegetation characteristics by use of ERS-1 Wind scatterometer over arid and semi arid areas," J. Hydrol., vol. 188-189, pp. 361-384, 1997.

[36] R. D. Magagi and Y. H. Kerr, "Estimating surface soil moisture and soil roughness from ERS-1 wind scatterometer data over semi-arid area: Use of the co-polarisation ratio," Remote Sens. Environ., vol. 75, no. 3, pp. 432-445, 2001.

[37] C. Gruhier, P. de Rosnay, S. Hasenauer, T. R. H. Holmes, R. de Jeu, Y. Kerr, E. Mougin, E. G. Njoku, F. Timouk, W. Wagner, and M. Zribi, "Soil moisture active and passive microwave products: Intercomparison and evaluation over a Sahelian site," Hydrol. Earth Syst. Sci., vol. 14, no. 1, pp. 141-156, 2010.

[38] T. J. Schmugge, J. R. Wang, and G. Asrar, "Results from the push broom microwave radiometer flights over the Konza Prairie in 1985," IEEE Trans Geosci. Remote Sens., vol. 26, no. 5, pp. 590-597, Sep. 1988.

[39] Y. H. Kerr and E. G. Njoku, "A semi-empirical model for interpreting microwave emission from semiarid land surfaces as seen from space," IEEE Trans. Geosci. Remote Sens., vol. 28, no. 3, pp. 384-393, May 1990.

[40] E. G. Njoku, T. L. Jackson, V. Lakshmi, T. Chan, and S. V. Nghiem, "Soil moisture retrieval from AMSR-E," IEEE Trans. Geosci. Remote Sens., vol. 41, no. 2, pp. 215-229, Feb. 2003.

[41] D. M. Le Vine and M. Haken, "RFI at L-band in synthetic aperture radiometers," presented at the IEEE Int. Geosci. Remote Sens. Symp., Toulouse, France, Jul. 21-25, 2003.

[42] J. P. Wigneron, Y. Kerr, and L. Prévot, "Retrieval of soil and vegetation features from passive microwave measurements," Remote Sens. Rev., vol. 15, pp. 157-177, 1997.

[43] J. P. Wigneron, Y. Kerr, P. Waldteufel, K. Saleh, M. J. Escorihuela, P. Richaume, P. Ferrazzoli, P. de Rosnay, R. Gurney, J. C. Calvet, J. P. Grant, M. Guglielmetti, B. Hornbuckle, C. Matzler, T. Pellarin, and M. Schwank, "L-band microwave emission of the biosphere (L-MEB) model: Description and calibration against experimental data sets over crop fields," Remote Sens. Environ., vol. 107, pp. 639-655, 2007.

[44] J.-P. Wigneron, J.-C. Calvet, P. de Rosnay, Y. Kerr, P. Waldteufel, K. Saleh, M. J. Escorihuela, and A. Kruszewski, "Soil moisture retrievals from biangular L-band passive microwave observations," IEEE Geosci. Remote Sens. Lett., vol. 1, no. 4, pp. 277-281, Oct. 2004.

[45] M. Schwank, M. Stähli, H. Wydler, J. Leuenberger, C. Mätzler, and H. Flühler, "Microwave L-Band emission of freezing soil," IEEE Trans Geosci. Remote Sens., vol. 42, no. 6, pp. 1252-1261, Jun. 2004.

[46] T. P. Boyer, J. I. Antonov, H. E. Garcia, D. R. Johnson, R. A. Locarnini, A. V. Mishonov, M. T. Pitcher, O. K. Baranova, and I. V. Smolyar, World Ocean Database 2005. Washington, DC: U.S. Government Printing Office, 2006, DVD

[47] T. P. Boyer, S. Levitus, J. I. Antonov, R. A. Locarnini, and H. E. Garcia, "Linear trends in salinity for the World Ocean, 1955-1998," Geophys. Res. Lett., vol. 32, no. 1, Art No. L01604, Jan. 6, 2005, DOI: 10.1029/ 2004GL021791.

[48] D. Roemmich, G. C. Johnson, S. Riser, R. Davis, J. Gilson, W. B. Owens, S. L. Garzoli, C. Schmid, and M. Ignaszewski, "The Argo program observing the Global Ocean with profiling floats," Oceanography, vol. 22, pp. 34-43, 2009.

[49] G. Reverdin, P. Blouch, J. Boutin, P. Niiler, J. Rolland, W. Scuba, A. Lourenco, and A. Rios, "Surface salinity measurements-COSMOS 2005 experiment in the Bay of Biscay," J. Atmos. Ocean. Technol., vol. 24, pp. 1643-1654, 2007.

[50] L. A. Klein and C. T. Swift, "An improved model for the dielectric constant of sea water at microwave frequencies," IEEE Trans. Antennas Propag., vol. AP-25, no. 1, pp. 104-111, Jan. 1977.

[51] J. Font, A. Camps, A. Borges, M. Martin-Neira, J. Boutin, N. Reul, Y. H. Kerr, A. Hahne, and S. Mecklenburg, "SMOS: The challenging sea surface salinity measurement from space," IEEE Proc., 2009, DOI: 10.1109/JPROC.2009. 2033096.

[52] J. Boutin, P. Waldteufel, N. Martin, G. Caudal, and E. Dinnat, "Salinity retrieved from SMOS measurements over Global Ocean: Imprecisions due to surface roughness and temperature uncertainties," J. Atmos. Ocean. Technol., vol. 21, pp. 1432-1447, 2004.

[53] N. Skou, "Atmospheric corrections for SSS retrievals," presented at the 8th Specialist Meeting on Microwave Radiometry and Remote Sensing Applications, Roma, Italy, Feb. 24-27, 2004.

[54] N. Skou, "Faraday rotation and L-band oceanographic measurements," Radio Sci., vol. 38, no. 4, p. 8059, DOI: $10.1029 /$ 2002RS002671.

[55] J. Boutin, P. Waldteufel, N. Martin, Y. Kerr, G. Caudal, E. Dinnat, and J. Etcheto, "Uncertainties on salinity retrieved from SMOS measurements over Global Ocean," presented at the IEEE Int. Geosci. Remote Sens. Symp., Toulouse, France, Jul. 21-25, 2003.

[56] D. Le Vine, A. Saji, Y. H. Kerr, W. J. Wilson, N. Skou, and S. Sobjaerg, "Comparison of model predictions with measurements of galactic background noise at L-band," IEEE Geosci. Remote Sens., vol. 43, no. 9, pp. 2018-2023, Sep. 2005.

[57] S. Zine, J. Boutin, J. Font, N. Reul, P. Waldteufel, C. Gabarro, J. Tenerelli, P. Petitcolin, J.-L. Vergely, and M. Talone,
"Overview of the SMOS sea surface salinity prototype processor," IEEE Geosci. Remote Sens., vol. 46, no. 3, pp. 2061-2072, Mar. 2008.

[58] N. Reul, J. Tenerelli, N. Floury, and B. Chapron, "Earth viewing L-band radiometer sensing of sea surface scattered celestial sky radiation. Part II: Application to SMOS," IEEE Trans. Geosci. Remote Sens., vol. 46, no. 3, pp. 659-674, Mar. 2008, DOI: 10.1109/TGRS.2007.914804.

[59] N. Reul, J. Tenerelli, B. Chapron, and P. Waldteufel, "Modelling sun glitter at L-band for the sea surface salinity remote sensing with SMOS," IEEE Trans. Geosci. Remote Sens., vol. 45, no. 7, pt. 1, pp. 2073-2087, Jul. 2007.

[60] H. Drange, P. Schlüssel, and M. Srokosz, "Study of critical requirements for ocean salinity retrieval using a low frequency microwave radiometer," ESTEC Noordwijk, The Netherlands, NL ESA Contract No. 13224/NL/MV, Apr. 1999.

[61] S. Philipps and C. Boone, "Impact of SMOS space-time averaging on sea surface salinity retrieval," presented at the IEEE Int. Geosci. Remote Sens. Symp., Toulouse, France, 2003.

[62] G. Lagerloef, F. R. Colomb, D. Le Vine, F. Wentz, S. Yueh, C. Ruf, J. Lilly, J. Gunn, Y. Chao, A. deCharon, G. Feldman, and C. Swift, "The Aquarius/Sac-D mission: Designed to meet the salinity remote-sensing challenge," Oceanography, vol. 21, pp. 68-81, 2008.

[63] D. Entekhabi, E. G. Njoku, P. Houser, M. Spencer, T. Doiron, Y. J. Kim, J. Smith, R. Girard, S. Belair, W. Crow, T. J. Jackson, Y. H. Kerr, J. S. Kimball, R. Koster, K. C. McDonald, P. E. O'Neill, T. Pultz, S. W. Running, J. C. Shi, E. Wood, and J. van Zyl, "The hydrosphere state (Hydros) satellite mission: An earth system pathfinder for global mapping of soil moisture and land freeze/thaw," IEEE Trans. Geosci. Remote Sens., vol. 42, no. 10, pp. 2184-2195, Oct. 2004.

[64] P. Thibaut and Y. H. Kerr, "Application of aperture synthesis in passive microware remote sensing," presented at the URSI Commission F: Signature Problems in Microwave Remote Sensing, Hyannis, MA, May 15-17, 1990.

[65] J. M. Goutoule, E. Anterrieu, Y. H. Kerr, A. Lannes, and N. Skou, "MIRAS microwave radiometry critical technical development," MMS, Toulouse, France, Executive Summary, Dec. 1996.

[66] F. Bayle, J. P. Wigneron, Y. H. Kerr, P. Waldteufel, E. Anterrieu, J. C. Orlhac, A. Chanzy, O. Marloie, M. Bernardini, S. Sobjaerg, J. C. Calvet, J. M. Goutoule, and N. Skou, "Two-dimensional synthetic aperture images over a land surface scene," IEEE Trans. Geosci. Remote Sens., vol. 40, no. 3, pp. 710-714, Mar. 2002.

[67] P. Waldteufel, J. Boutin, and Y. Kerr, "Selecting an optimal configuration for the soil moisture and ocean salinity mission," Radio Sci., vol. 38, no. 3, p. 8051, DOI: 10. 1029/2002RS002744.

[68] Y. H. Kerr, P. Waldteufel, J.-P. Wigneron, J. Martinuzzi, J. Font, and M. Berger, "Soil moisture retrieval from space: The Soil Moisture and Ocean Salinity (SMOS) mission," IEEE Trans. Geosci. Remote Sens., vol. 39, no. 8, pp. 1729-1735, Aug. 2001.

[69] J.-P. Wigneron, P. Waldteufel, A. Chanzy, J. C. Calvet, and Y. Kerr, "Two-D microwave interferometer retrieval capabilities of over land surfaces (SMOS Mission)," Remote Sens. Environ., vol. 73, pp. 270-282, 2000. 
[70] K. D. McMullan, M. A. Brown, M. Martin-Neira, W. Rits, S. Ekholm, J. Marti, and J. Lemanczyk, "SMOS: The payload," IEEE Trans. Geosci. Remote Sens., vol. 46, no. 3, pp. 594-605, Mar. 2008.

[71] Y. Kerr and P. Waldteufel, "SMOS level 2 processor high level requirements," CBSA Toulouse, France, SO-TN-CBSA-GS-0003, ver. 2b, Jul. 20, 2004

[72] Y. Kerr and P. Waldteufel, "Mission products and data processing requirements for SMOS," CBSA, Toulouse, France, SO-TN-CBSA-GS-000, ver. 1.a, Feb. 17, 2003.

[73] E. Anterrieu, "A resolving matrix approach for synthetic aperture imaging radiometers," IEEE Trans Geosci. Remote Sens., vol. 42, no. 8, pp. 1649-1656, Aug. 2004.

[74] Y. H. Kerr, P. Waldteufel, P. Richaume, P. Ferrazzoli, and J. P. Wigneron, "SMOS level 2 processor soil moisture algorithm theoretical basis document (ATBD)," CESBIO, Toulouse, France, ATBD SO-TN-ESL-SM-GS-0001, V3.a, Oct. 15, 2008

[75] J. Font, J. Boutin, N. Reul, P. Waldteufel, C. Gabarró, S. Zine, and J. Tenerelli, "SMOS sea surface salinity level 2 algorithm theoretical baseline document," Noordwijk, The Netherlands, NL ESTEC Contract 18933/05/NL/FF, 2007.

[76] J. M. Sabater, C. Rudiger, J. C. Calvet, N. Fritz, L. Jarlan, and Y. Kerr, "Joint assimilation of surface soil moisture and LAI observations into a land surface model," Agricultural Forest Meteorol., vol. 148, pp. 1362-1373, 2008.

[77] O. Merlin, A. Chehbouni, Y. H. Kerr, and D. C. Goodrich, "A downscaling method for distributing surface soil moisture within a microwave pixel: Application to the Monsoon '90 data," Remote Sens. Environ., vol. 101, pp. 379-389, 2006.

[78] O. Merlin, J. P. Walker, A. Chehbouni, and Y. Kerr, "Towards deterministic downscaling of SMOS soil moisture using MODIS derived soil evaporative efficiency," Remote Sens. Environ., vol. 112, pp. 3935-3946, 2008.

[79] P. Ferrazzoli, L. Guerriero, and J.-P. Wigneron, "Simulating L-band emission of forests in view of future satellite applications," IEEE Trans. Geosci. Remote Sens., vol. 40, no. 12 , pp. $2692-2708$, Dec. 2002.
[80] J. P. Grant, K. Saleh-Contell, J. P. Wigneron, M. Guglielmetti, Y. H. Kerr, M. Schwank, N. Skou, and A. A. V. de Griend, "Calibration of the L-MEB model over a coniferous and a deciduous forest," IEEE Trans. Geosci. Remote Sens., vol. 46, no. 3, pp. 808-818, Mar. 2008.

[81] K. Saleh, J. P. Wigneron, P. Waldteufel, P. de Rosnay, M. Schwank, J. C. Calvet, and Y. H. Kerr, "Estimates of surface soil moisture under grass covers using L-band radiometry," Remote Sens. Environ., vol. 109, pp. 42-53, 2007.

[82] K. Saleh, J. P. Wigneron, P. de Rosnay, J. C. Calvet, and Y. Kerr, "Semi-empirical regressions at L-band applied to surface soil moisture retrievals over grass," Remote Sens. Environ., vol. 101, pp. 415-426, 2006.

[83] A. Mialon, L. Coret, Y. H. Kerr, F. Secherre, and J. P. Wigneron, "Flagging the topographic impact on the SMOS signal," IEEE Trans. Geosci. Remote Sens., vol. 46, no. 3 , pp. 689-694, Mar. 2008.

[84] M. A. Brown, F. Torres, I. Corbella, and A. Colliander, "SMOS calibration," IEEE Trans. Geosci. Remote Sens., vol. 46, no. 3, pp. 646-658, Mar. 2008.

[85] A. Colliander, L. Ruokokoski, J. Suomela, K. Veijola, J. Kettunen, V. Kangas, A. Aalto, M. Levander, H. Greus, M. T. Hallikainen, and J. Lahtinen, "Development and calibration of SMOS reference radiometer," IEEE Trans. Geosci. Remote Sens., vol. 45, no. 7, pt. 1, pp. 1967-1977, Jul. 2007

[86] F. Cabot, Y. H. Kerr, and P. Waldteufel, "Calibration of SMOS geolocation biases," in Proc. IEEE Int. Geosci. Remote Sens. Symp., 2007, vol. 1-12, pp. 4448-4450.

[87] S. Delwart, C. Bouzinac, P. Wursteisen, M. Berger, M. Drinkwater, M. Martin-Neira, and Y. H. Kerr, "SMOS validation and the COSMOS campaigns," IEEE Trans. Geosci. Remote Sens., vol. 46, no. 3, pp. 695-704, Mar. 2008

[88] K. Saleh, Y. H. Kerr, G. Boulet, P. Maisongrande, P. de Rosnay, D. Floricioiu, M. J. Escorihuela, J. P. Wigneron, A. Cano, E. Lopez-Baeza, J. P. Grant, J. Balling, N. Skou, M. Berger, S. Delwart, P. Wursteisen, R. Panciera, and J. P. Walker, "The CoSMOS L-band experiment in Southeast Australia," in Proc. IEEE Int. Geosci. Remote Sens. Symp., vol. 1-12, Sensing and Understanding Our Planet, 2007, pp. 3948-3951.
[89] N. Reul, J. Tenerelli, S. Guimbard, N. Skou, S. Søbjaerg, E. Cardellach, P. Wursteisen, C. Bouzinac, F. Collard, B. Chapron, and J. Tournadre, "COSMOS OS campaign. Scientific data analysis report, Noordwijk, The Netherlands, ESA ESTEC 1-4505/03/NL/Cb, 2007.

[90] P. Wursteisen, P. Fletcher, and European Space Agency, Proc. 1st Results Workshop EuroSTARRS, WISE, LOSAC, Toulouse, France, Nov. 4-6, 2002, vol. 525, pp. 3-5.

[91] E. Lopez-Baeza, M. Berger, P. Wursteisen, J.-C. Calvet, J. Etcheto, J. Font, Y. Kerr, J. Miller, J.-P. Wigneron, L. Simmonds, C. Antolín Tomás, J. F. Ferrer, K. S. Contell, J. Boutin, T. Pellarin, J. Wesson, and B. E. Main, "The EuroSTARRS-2001 aircraft campaign of the european space agency in support of the SMOS mission," presented at the III Congr. Spanish Assoc. Climatol., Palma de Mallorca, Spain, 2002.

[92] M. R. Drinkwater, N. Floury, and M. Tedesco, "L-band ice-sheet brightness temperatures at Dome C, Antarctica: Spectral emission modelling, temporal stability and impact of the ionosphere," Ann. Glaciol., vol. 39, pp. 391-396, 2005.

[93] G. Macelloni, P. Pampaloni, M. Brogioni, E. Santi, A. Cagnati, and M. Drinkwater, "DOMEX 2004: An Experimental campaign at dome-C Antarctica for the calibration of space-borne low-frequency microwave radiometers," presented at the IEEE Int. Geosci. Remote Sens. Symp., Seoul, South Korea, Jul. 25-29, 2005.

[94] P. de Rosnay, J. C. Calvet, Y. Kerr, J. P. Wigneron, F. Lemaitre, M. J. Escorihuela, J. M. Sabater, K. Saleh, J. L. Barrie, G. Bouhours, L. Coret, G. Cherel, G. Dedieu, R. Durbe, N. E. D. Fntz, F. Froissard, J. Hoedjes, A. Kruszewski, F. Lavenu, D. Suquia, and P. Waldteufel, "SMOSREX: A long term field campaign experiment for soil moisture and land surface processes remote sensing," Remote Sens. Environ., vol. 102, pp. 377-389, 2006.

[95] Y. H. Kerr, B. Rougé, F. Cabot, P. Richaume, J.-C. Souyris, and E. Anterrieu, "SMOS NEXT: The new generation," presented at the 11th Specialist Meeting Microw. Remote Sens. Environ, Washington, DC, Mar. 1-4, 2010 .

\section{ABOUT THE AUTHORS}

Yann H. Kerr (Senior Member, IEEE) received the engineering degree from Ecole Nationale Supérieure de l'Aéronautique et de I'Espace (ENSAE), Toulouse, France, in 1977, the M.Sc. degree in electrical and electronic engineering from Glasgow University, Glasgow, U.K., in 1981, and the Ph.D. degree from Université Paul Sabatier, Toulouse, France, in 1992.

From 1980 to 1985, he was employed by CNES. In 1985 he joined LERTS, where he was the Director in 1993-1994. He spent 19 months at the Jet Propulsion Laboratory (JPL), Pasadena, CA, in 1987-1988. He has been working at CESBIO since 1995 (Deputy Director and Director since 2007). His fields of interest are in the theory and techniques for microwave and thermal infrared remote sensing of the Earth, with emphasis on hydrology, water

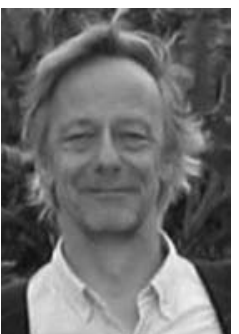

resources management, and vegetation monitoring. He has been involved with many Space missions. He was an EOS principal investigator (interdisciplinary investigations) and Principal Investigator and precursor of the use of the SCAT over land. In 1990, he started to work on the interferometric concept applied to passive microwave earth observation and was subsequently the science lead on the MIRAS project for the European Space Agency (ESA) with Matra Marconi Space and Observatoire Midi Pyrénées. He was also a Coinvestigator on IRIS, OSIRIS, and HYDROS for NASA. He was science advisor for MIMR and Coinvestigator on AMSR. In 1997, he first proposed the natural outcome of the previous MIRAS work with what was to become the SMOS Mission which was eventually selected by ESA in 1999 with him as the SMOS mission LeadInvestigator and Chair of the Science Advisory Group. He is also in charge of the SMOS science activities coordination in France. He has organized all the SMOS Science workshops. 
Philippe Waldteufel received a degree from École Polytechnique, Palaiseau Cedex, France, in 1962 and the Doctorat d'État from the Université de Paris, Paris, France, in 1970.

$\mathrm{He}$ is a Senior Scientist Emeritus at Centre National de la Recherche Scientifique, Verrières le Buisson. His main scientific interests have been ionospheric and thermospheric physics, radar meteorology, radiowave propagation, macroeconomics, and finally microwave radiometry. He has

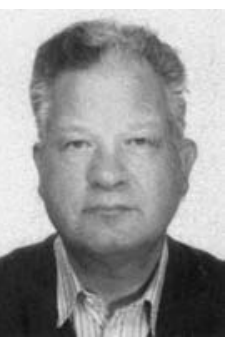
also served as Director of the Institut de Physique du Globe de ClermontFerrand, Deputy Director in the French Weather Service Research Department, and Director for Science in the French Research Ministry. He cosigned to the original SMOS proposal in 1997.

Jean-Pierre wigneron (Senior Member, IEEE) received the M.Sc./Engineering degree from SupAéro, Ecole Nationale Supérieure de l'Aéronautique et de I'Espace (ENSAE), Toulouse, France, in 1987 and the Ph.D. degree from University of Toulouse, Toulouse, France, in 1993.

Currently, he is a Senior Research Scientist at the Institut National de Recherche Agronomiques (INRA), Bordeaux, France, Co-Coordinator of Inra Remote Sensing activities and the Head of the

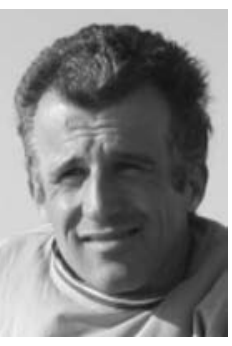
remote sensing team at EPHYSE, Bordeaux. He coordinated the development of the L-MEB model for soil and vegetation in the level 2 inversion algorithm of the European Space Agency (ESA) SMOS mission. His research interests are in microwave remote sensing of soil and vegetation, radiative transfer, and data assimilation. He has more than 80 papers in international peer-reviewed journals

Dr. Wigneron has been a member of the Editorial Board of Remote Sensing of Environment since 2005.

Steven Delwart was born in the U.S. in 1957. He received the B.Sc. (honors) degree in physics and the M.Sc. degree in optics from the Imperial College, University of London, U.K., in 1982.

In 1993, he started his career at Lockheed Missiles and Space Research Laboratories, Palo Alto, CA, in the Advanced Surveillance Department, where he was involved in the development and later made responsible for the calibration of an airborne Infra-Red imaging spectrometer. In

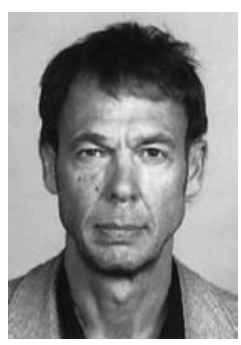
1988, he joined Orlikon-Bhurle Laser division in Switzerland, to develop low power $\mathrm{CO}_{2}$ laser applications, derived from the Air Defense Anti Tank missile System (ADATS) laser head. In 1993, he joined the European Space Agency (ESA) as a performance engineer for the Medium Resolution Imaging Spectrometer (MERIS) on board ENVISAT, where he was responsible for the development of both the engineering and scientific algorithms, including calibration. His involvement in SMOS started in 2004, with the development of the scientific algorithms, and the coordination of the validation team. He will be managing the algorithm evolution and data product validation activities for SMOS, during the exploitation phase.
François Cabot received the Ph.D. degree in optical sciences from the University of Paris-Sud, Orsay, France in 1995.

Between 1995 and 2004, he was with CNES wide field of view instruments quality assessment department, working on absolute and relative calibration of CNES-operated optical sensors over natural terrestrial targets. In 2004, he joined CESBIO as SMOS System Performance Engineer. $\mathrm{His}$ research interests are in radiative transfer

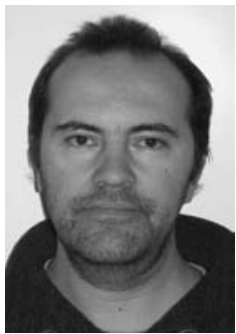
both optical and microwave and remote sensing of terrestrial surfaces. He has been a Principal Investigator or Co-Investigator for various calibration studies for MSG, Terra, ENVISAT, and ADEOS-II.

Jacqueline Boutin received the Ph.D. degree in physical methods in remote sensing from the University Paris VII, Paris, France, in 1990.

Currently, she is Research Director at CNRS/ Laboratoire d'Océanographie et du ClimatExpérimentations et Approches Numériques, Paris, France. She has widely studied the validity of remotely sensed wind speeds and the ocean/ atmosphere exchange of CO at large scale using both satellite (wind speed, SST, ocean color) and

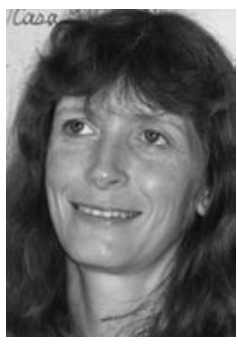
in situ data. Since 1999, she has been involved in the preparation of the SMOS mission and has focused on the retrieval of ocean salinity from L-band measurements.
Maria-José Escorihuela received the engineering degree in electronics and telecommunications from the Universitat Politècnica de Catalunya, Barcelona, Spain and the Ph.D. degree from the Institut National Polytechnique, Toulouse, France, in 2006.

From 2003 to 2006, she was with the Centre d'Etudes Spatiales de la Biosphère (CESBIO), Toulouse, France, where she was developing models of natural surfaces emission at L-band

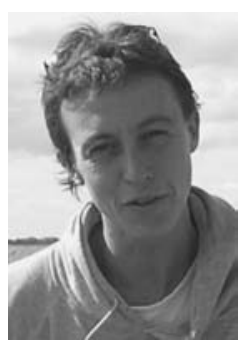
for soil moisture estimation in the framework of the SMOS mission preparation and actively involved in the SMOSREX field experiment. Currently, she is in IsardSAT, Barcelona, Spain. Her scientific fields of interest are the application of passive and active microwave remote sensing to hydrology and climate change studies. 
Jordi Font received the B.Sc. and Ph.D. degrees in physics from the University of Barcelona, Barcelona, Spain, in 1973 and 1986, respectively.

$\mathrm{He}$ is a Senior Researcher with the Physical Oceanography Department, Institut de Ciències del Mar, Spanish Research Council, Consejo Superior de Investigaciones Cientificas (CSIC), Barcelona, Spain. He is the author or coauthor of 125 published papers and 300 communications to scientific symposia. He is the advisor for nine Ph.D.

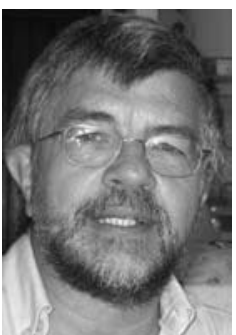
dissertations. He has been Principal Investigator in several Spanish and European research contracts. He is currently the Colead Investigator for ocean salinity in the European Space Agency SMOS mission. Moreover, he is also the Chairman of the Physics and Climate of the Ocean Committee of the International Commission for the Scientific Exploration of the Mediterranean Sea. His main research activities include the study of ocean remote sensing (determination of sea surface salinity by microwave radiometry), physical oceanography of the Mediterranean Sea (water masses, circulation, and climate change), ocean circulation (operational measurements of ocean currents, technological improvements), and mesoscale dynamics (fronts, eddies, topographic interactions, physical-biological processes coupling).

Dr. Font is a member of several international societies and committees and a participant in 42 oceanographic campaigns.

Nicolas Reul received the B.S. degree in marine science engineering from Toulon University, Toulon, France, in 1993 and the Ph.D. degree in fluid mechanics from the University of Aix-Marseille II, Marseille, France, in 1998.

From 1999 to 2001, he was with the Department of Applied Marine Physics, Rosenstiel School of Marine and Atmospheric Science, University of Miami, Miami, FL, as a Postdoctoral Research Associate. In 2000, he moved to the Institut

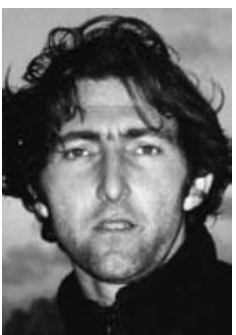
Français de Recherche et d'Exploitation de la Mer (IFREMER), France, as a Postdoctoral Research Associate. He took a permanent research scientist position in 2001 in IFREMER's Laboratoire d'Océanographie Spatiale. His current professional interests involve air-sea interaction processes, ocean surface waves, ocean surface microwave remote sensing measurements and theory, and in particular, sea surface salinity remote sensing with microwave radiometry. He is responsible at IFREMER for a project focussed on sea surface salinity remote sensing with the European Space Agency (ESA) SMOS mission. He provided scientific support to the development of ESA and CNES SMOS salinity levels 2, 3, and 4 product ground segment development. He is also member of the SMOS mission Science Advisory Group (SAG) for ESA. He has experience in applied mathematics, physical oceanography, and electromagnetic wave theory and its application to ocean remote sensing.

Claire Gruhier received the M.S. degree in remote sensing and GIS applied to environmental sciences from the Denis Diderot University, Paris, France, in 2006. She is currently working towards the Ph.D. degree at the Centre d'Etudes Spatiales de la BIOsphère (CESBIO), Toulouse, France, and the Pierre et Marie Curie University of Paris IV.

Her research interests focus on validation and intercomparison of soil moisture products based on microwaves measurements over Sahelian area (AMMA sites) in the context of the SMOS mission.

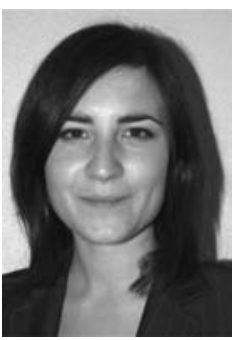

Silvia Enache Juglea received the engineering degree in electronics and telecommunication from Politehnica University of Timisoara, Romania and the M.S. degree in microwave, electromagnetism, and optoelectronics from the University Paul Sabatier-Toulouse III, France, in 2005 and 2007, respectively. She is currently working towards the Ph.D. degree at the Centre d'Etudes Spatiales de la BIOsphère (CESBIO), Toulouse, France.

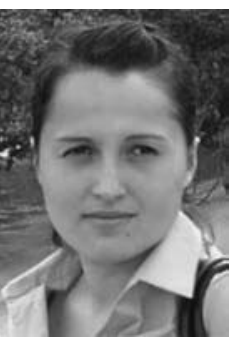

Her current fields of interest include soil moisture and passive microwave modeling in the framework of SMOS mission.

Mark R. Drinkwater (Member, IEEE) was born in the U.K. in 1963. He received the B.Sc. (honors) degree from the University of Durham, Durham, U.K., in 1984 and the Ph.D. degree from the University of Cambridge, Cambridge, U.K., in 1988.

In 1987 he was Research Consultant with the Science Applications International Corporation, Cambridge, U.K. In 1988, he moved to the Institute of Technology, Jet Propulsion Laboratory (JPL), Pasadena, CA, as a Resident Research Associate

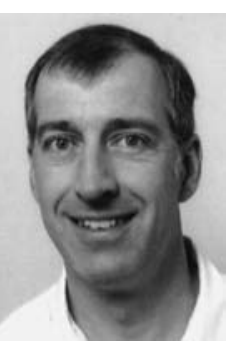
with the support of the U.S. National Research Council. He took a permanent research scientist position in 1990 in JPL's Earth and Space Science Division. From 2000 he was Principal Investigator on a number of international research projects with NASA, ESA, CSA, and JAXA and participated in several polar research expeditions. In 2000, he joined the European Space Agency (ESA) as Head of the Oceans/Ice unit of the Earth Observation Programmes Directorate at the European Space Research and Technology Centre (ESTEC), Noordwijk, The Netherlands. In 2007, he became Head of the Mission Science Division, with responsibility for scientific preparations in support of development of ESA's Earth Explorer satellite series, including GOCE, SMOS, CryoSat, ADM-Aeolus, Swarm, EarthCARE, and the ESA-EU GMES Sentinel satellite series. His current professional interests involve SAR altimetry retrievals of ice elevation and sea-ice thickness and ocean salinity from L-band satellite microwave interferometer data, and the measurement of gravity gradients using satellite gradiometry.

Dr. Drinkwater is an member of the IEEE Geoscience and Remote Sensing Society, the Electromagnetics Academy, the International Glaciological Society, and the American Geophysical Union (AGU). He has served as an Editor of AGU's Journal of Geophysical Research, Oceans and as a guest Editor of various journal special issues.

Achim Hahne graduated in atmospheric chemistry from the Nuclear Research Centre, Jülich, Germany and received the Ph.D. degree in material sciences from Aachen Technical University, Aachen, Germany.

In 1983, he joined the European Space Agency (ESA). After initial positions in the Space Science and the Technical Directorates, he transferred to the Earth Observation programs Directorate where he worked on the ERS, ENVISAT, and

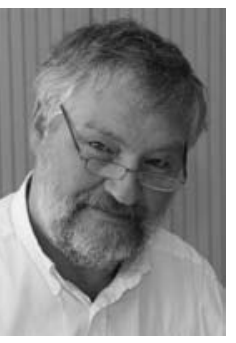
METOP projects. He has been the SMOS Project Manager since 2002. 
Manuel Martín-Neira received the M.S. and Ph.D. degrees in telecommunication engineering from the School of Telecommunication Engineering, Polytechnic University of Catalonia, Spain, in 1986 and 1996 respectively.

He was awarded a fellowship to work on radiometry at the European Space Research and Technology Center (ESTEC), Noordwijk, The Netherlands, in 1988. From 1989 to 1992, he was with GMV, a Spanish firm, where he was responsible for several

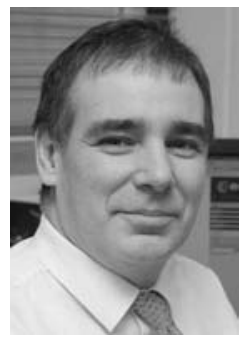

projects for the European Space Agency (ESA) related to GPS spacecraft navigation with applications to precise landing and attitude determination. Since 1992, with ESA, he has been in charge of the radiometer activities within the Payload, Equipment, and Technology Section. During this period he has also developed new concepts for constellations of small satellites for Earth observation. In particular, he holds several patents related to aperture synthesis radiometry and on the PARIS concept for the use of GNSS signals reflected from the ocean. Since 2001, he has been the Instrument Principal Engineer of ESA's Soil Moisture and Ocean Salinity Earth Explorer Opportunity Mission.

Dr. Martín-Neira received the Confirmed Inventor Award from the director of ESA in 2002 and has been a member of the Academie des Technologies of France since 2009.
Susanne Mecklenburg received the M.S. degree in hydrology from the Technical University of Dresden, Dresden, Germany in 1997 and the Ph.D. degree in atmospheric science from the Swiss Institute of Technology, Zurich, Switzerland, in 2000.

She joined the European Space Agency (ESA) in 2008 to take up the position of SMOS Mission Manager. Before joining ESA, she worked in the U.K. with the British National Space Centre.

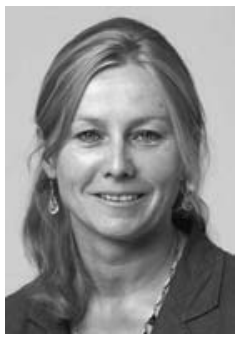

